\title{
IMPACT OF SEISMIC PROVISIONS IN DIFFERENT EDITIONS OF THE EGYPTIAN CODE OF LOADS
}

\author{
Waleed Abo El-Wafa Mohamed \\ Lecturer, Civil Engineering Department, Faculty of Engineering, Assiut \\ University, Assiut, Egypt.
}

(Received June 15, 2009 Accepted June 29, 2009).

\begin{abstract}
The last edition of the Egyptian Code of Loads (ECOL) was released by the end of year 2008. The seismic provisions in this edition are almost completely different compared with those in the 1993 edition while some specific changes are presented relative to the 2003 edition. The major significant changes in the seismic provisions revealed in the different editions are reviewed. The impact of these provisions on the level of seismic protection for different types of structures with different heights is analyzed and discussed. An analytical analysis is carried out to compare and verify the applicability of these methods and the protection level they introduce. The modal response spectrum (MRS) analysis is carried out using the elastic design spectrum specified by the 2008 ECOL while the time history analysis (THA) is applied using seven different real earthquake excitations selected to match the specified elastic spectrum and soil type. Suggestion to rationally enhance the seismic protection level obtained from the multiple response spectrum is presented and emphasized. This study extends to analyze and compare our seismic provisions with those appeared in different international codes for sites with similar conditions. It is found that the provisions in the 1993 edition yield base shear much less than the values obtained using 2008 edition especially for low to medium height buildings located in medium and high seismic zones. Also, it is found that some provisions in the new edition need to be urgently reconsidered.
\end{abstract}

KEYWORDS: Seismic codes, ECOL, seismic analysis methods, response modification factor, seismic provisions.

\section{INTRODUCTION}

Earthquake tremors usually induce loads which trigger the structure to respond in such a dynamic phenomenon which depends on the intensity, duration, and frequency content of the exciting motion as well as the dynamic characteristics of structures. Building codes recommend using either equivalent load method, due to its simplicity, or multi modal response spectrum method. Time history analysis, either linear or nonlinear, is usually an optional method. The use of static load analysis in establishing seismic design quantities is justified because of the complexities associated with dynamic analysis. Although the ability to carry out nonlinear analysis has seen significant improvement recently, considerable uncertainty arises in modeling the nonlinear behavior of structural materials and components. In addition, nonlinear response to two different ground motions may differ significantly. In view of the 
difficulties associated with nonlinear analysis, linear dynamic analysis is often carried out to determine the design forces. Computer programs that are capable of carrying out a linear dynamic analysis, either a time-history or a multi modal response analysis, are widely available, and designers are becoming increasingly comfortable in using them.

The first edition of the ECOL [1] containing seismic provisions was issued in 1993. These provisions were highly influenced by concepts presented by the Uniform Building Code $U B C-85$ [2], however, some provisions in the $U B C-85$ were modified to suit the seismicity nature and soil types in Egypt. In this code, the seismic base shear was seen to be a percentage of the total dead load of the structure. This percentage depends on the site seismicity, soil condition, the utilization importance, fundamental period and the type of seismic force resisting system. A seismic map which classifies Egypt into three different zones was provided. In this code, the equivalent static load (ESL) method was the dominant design method which could be used for structures having uniform lateral load resisting systems up to $100 \mathrm{~m}$. Otherwise, modal spectrum response, under some restrictions, and time history analysis are mandatory required methods. However, the results obtained using the modal analysis method are limited to $80 \%$ of the base shear calculated using the ESL method. In this edition, no design response spectrum neither provisions for the selected ground excitation is presented.

The second edition of this code, 2003 ECOL [3], was issued in 2003. The seismic loads on buildings included in this code were basically relying on the Eurocode-8 [4], January 2001 edition. The seismic provisions in this edition had experienced major significant changes. Egypt had been divided into five seismic regions according to design ground acceleration $\left(a_{g}\right)$ which ranges from $0.1 \mathrm{~g}$ to $0.25 \mathrm{~g}$. Two types of elastic response spectrum are provided, type 1 which is valid for all regions and type 2 which is valid to coastal cities along the Mediterranean sea. Mainly, this edition adopted the concept of multi modal response spectrum (multi MRS) as the basic design method which is valid to all types of structures. ESL, (called in this code simplified MRS) method is still applicable but with higher restrictions. Using THA is also permitted but with certain conditions. Many new provisions related to analysis methods, structural regularity, combination of earthquake action components, nonstructural elements and safety verification are presented in that edition.

Finally, a modified version of this code, under same title, is revealed in September 2008. The seismic provisions in this code are almost, except some specific significant changes, similar to the provisions presented by the 2003 ECOL edition. These changes include appending a new seismic zone along with changing the seismic intensity of some towns. Some changes are also applied to the structural modeling, safety verification and period equations.

The continuous evolutions in seismic provisions revealed in national building codes always triggered the researchers enthusiasm to pursue and investigate the different provisions of such seismic codes. The effort of the researchers has been paid in many code related aspects. Examples, include seismic zone maps and code elastic response spectrum as [5] and [6] concerned with Eurocode- 8 and National building code of Canada $N B C C$, respectively. The response modification factor, may has different denominations, in many national codes attracted much attention as in [7], [8] and [9] which were concerned with Eurocode-8, UBC and Chinese codes, respectively. Comparative studies between national seismic provisions and international ones as Turkish Earthquake code and UBC [10], Eurocode- 8 and Japanese one [11] and set of 
different international codes [12] were also reported. The major significant changes in different national code editions were, sometimes, overviewed [13], [14]. The seismic provisions in previous ECOL editions have also attained the researchers attention dealing with specific items as suggested code fundamental period equations [15], [16], performance and ductility [17] and nonstructural elements [18], [19].

The continuous evolutions in the Egyptian seismic provisions motive such code related studies to be urgently accomplished to assess the impact of their variations on the level of seismic protection they introduce. Thus, the primary motivations for the present study are precisely as follows: (i) to overview the significant changes in the series of the seismic provisions of the ECOL. This is to be carried out along with investigating different building types as moment resisting frames (MRF) and shear wall-moment resisting frames (SW-MRF) designed using the ESL method (ii) to verify the level of seismic protection provided by the 2008 ECOL specified design response spectrum through conducting a comparative simplified and multi MRS analysis versus THA. The THA is applied using seven deliberate earthquake excitations match the code specified provisions and (iii) analytically compare our provisions with those appeared in the codes of different countries as Eurocode-8, UBC 97 and NBCC [13]. A particular emphasis is paid to evaluate the ECOL response modification factors compared with considered codes.

\section{SUMMARY OF MAJOR SEISMIC PROVISION CHANGES IN ECOL}

In the following section, the major changes that have been applied to the seismic provisions in the different ECOL editions from 1993 to 2008 are summarized and overviewed. For the purpose of easier comprehending of these changes, the base shear formulas and related parameters of the editions with major changes, 1993 and 2008 editions, are illustrated in Table 1 followed by a brief discussion.

Table 1: Base shear formulas in the 1993 and 2008 ECOL editions

\begin{tabular}{|l|l|l|}
\hline Parameter & \multicolumn{1}{|c|}{$1993 E C O L$} & \multicolumn{1}{|c|}{$2008 E C O L$} \\
\hline Equivalent static load & $V=Z . I . K . C . S . W$ & $\begin{array}{l}F_{b}=S_{d}\left(T_{I}\right) \lambda W / g ; S_{d}(T) \text { is the design } \\
\text { response spectrum which is related to } \\
a_{g}, \gamma_{I}, S, \eta, R, T \text { and spectrum periods. }\end{array}$ \\
\hline Seismic hazard parameter & $Z=0.1,0.2,0.3$ & $a_{g}=(0.1,0.125,0.15,0.2,0.25$ and 0.3$) \mathrm{g}$ \\
\hline Importance factor & $I=1$ or 1.25 & $\gamma_{I}=0.8,1,1.2$ and 1.4 \\
\hline Structural resisting system & $0.67 \leq K \leq 1.33$ & $2 \leq R \leq 7$ \\
\hline Site response factor & $S=1 ., 1.15$ or & $S$ is related to soil class and spectrum type \\
\hline Period effect & 1.3 & $S_{d}\left(T_{I}\right)$ is related to period $\left(T_{I}\right)$ \\
\hline Correction factor & $C=1 / 15 \sqrt{T}$ & $\lambda=0.85$ or 1.0 \\
\hline Damping correction & - & $0.95 \leq \eta \leq 1.2$ \\
\hline
\end{tabular}


The major evolution between 1993 edition and the later editions was remarked by the new adoption of the aspect of response spectrum acceleration anchored to PGA. The treatment of base shear formulation in the two versions of 2003 and 2008 ECOL is similar except the existence of importance factor $\gamma_{I}$ either in response spectrum or in base shear equation which yields final identical base shear. It is worth to mention here that the base shear obtained from 2003 and 2008 editions, rather than the 1993 edition, is ultimate load that when used in the elastic theory it must be reduced by a factor of 1.4 or 1.28 for 2008 and 2003 editions, respectively.

\subsection{Seismic Zones and Design Response Spectra}

The 1993 ECOL provided a seismic map which classifies Egypt to three different seismic zones, arranged from lower to higher seismicity, as zones I, II and III, respectively. A seismic intensity factor is identified for each zone, this factor takes the value $0.1,0.2$ and 0.3 for zone I, II and III, respectively.

The map was changed in the 2003 ECOL edition. An elastic response spectrum acceleration was constructed by anchoring a spectral shape defined for each site class to the design peak ground acceleration (PGA). The site classification in the new map was remarked by different five zones related to PGA acceleration of values range between $0.1 \mathrm{~g}$ to $0.25 \mathrm{~g}$. Two types of response spectrum were provided, Type 1 which is valid for all regions in the country and type 2 which is valid only for coastal cities along the Mediterranean sea. It is worth to mention here that type 1 spectrum in the 2003 ECOL is type 2 spectrum in Eurocode- 8 which was recommended by the later code for regions only affected by earthquakes of magnitude $M_{s}<5.5$. The 2003 type 2 spectrum is type 1 spectrum in Eurocode- 8 which, the later code, recommended for regions affected by larger events. Fig. 1 [20] compares type 2 spectral shape of Eurocode- 8 with median spectral ordinates for earthquakes of different magnitudes. The figure illustrates that the spectral shape will approximate that expected for a particular earthquake magnitude but then tend to over-and under-estimate the longer period ordinates for smaller and larger events, respectively. Fig. 2 Illustrates the two types of elastic spectrum for the different specified soil conditions, noting that the vertical axis is normalized to the PGA .

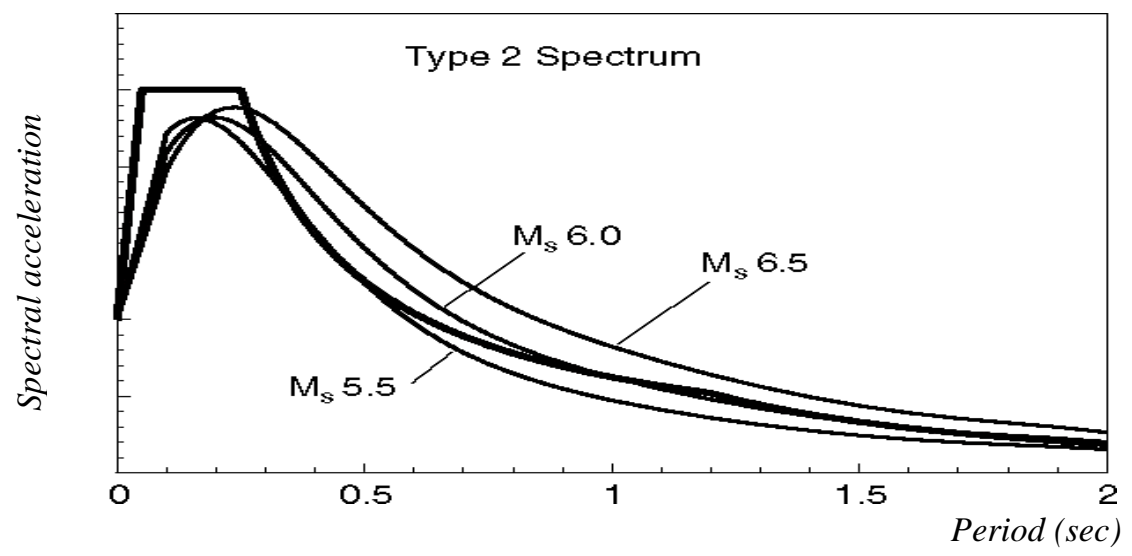

Fig. 1: Eurocode- 8 type 2 spectrum versus median earthquake spectrum (rock soil) 


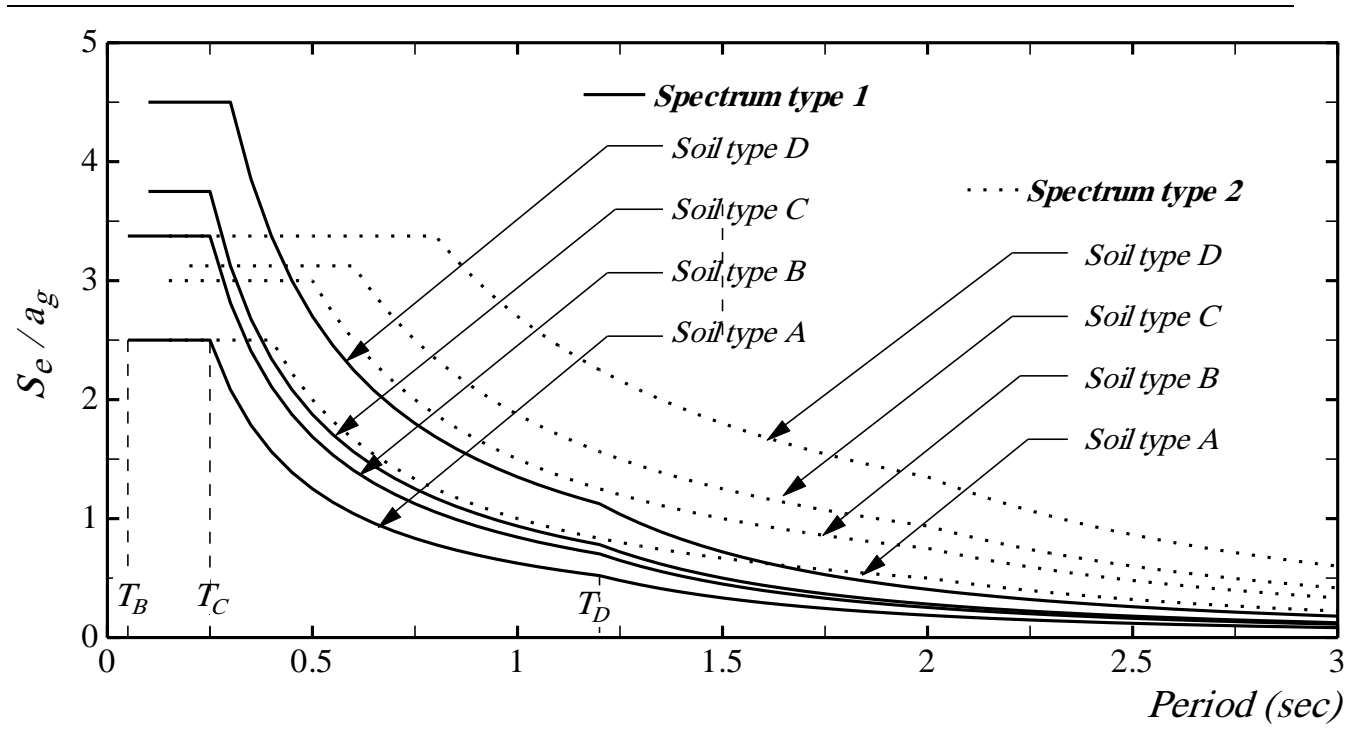

Fig. 2: The ECOL types 1 and 2 response spectrum for different site conditions

The 2008 ECOL continued using the same spectrum types while an additional zone was appended, zone 5 is divided into two classes which are zone 5a with $a_{g}$ equals $0.25 \mathrm{~g}$ and zone $5 \mathrm{~b}$ with $a_{g}$ equals 0.30 .

Many cities had experienced changes in the seismic zone intensities from 1993 ECOL to 2003 ECOL. Examples of governorates that witnessed downgrading in its seismic intensity, relative to the code index, include most of the cities in the upper Egypt and some cities along the Mediterranean sea. However, minor changes could be observed between the 2003 and 2008 editions, this change is remarked by increasing the intensity of two cities, Taba and Shidwan island, from $a_{g}=0.25 \mathrm{~g}$ to $0.30 \mathrm{~g}$.

\subsection{Soil Conditions}

The amplification of soil condition at a site can significantly affect the seismic hazard. In 1993 ECOL edition the effect of soil was related directly to the base shear equation through the factor $S$. This factor was defined by a largely qualitative description of the soil. Three soil profiles were arranged in order of increasing flexibility from rock to alluvium soil, the corresponding values of $S$ are shown in Table 1 . The construction of elastic spectrum in the $2003 E C O L$ edition is related to the soil conditions. In this edition, soil was classified into four ground types A, B, C and D, arranged from rock to loose soils. In this edition of code, soil is more precisely described using the undrained shear strength of soil, standard penetration test blow-count and shear wave velocity. However, it is permitted for low and normal importance buildings and those located in zones with low seismicity to use soil classification C. Otherwise, soil experiments should be carried out.

\subsection{Period Determination}

The fundamental period $T$ is an important design parameter that plays a significant role in the computation of design base shear either directly as the case in 1993 ECOL or determine the values needed to construct the spectral response acceleration for other 
editions. The value of $T$ should not be overestimated as this results in an underestimation of the seismic design forces.

In addition to the possible available methods, two equations were permitted by the 1993 ECOL to calculate the fundamental period. The first for MRF which related $T$ to the number of floors $(N)$ as:

$T=0.1 N$

The second equation is adopted for other building types as:

$T=\frac{0.09 H}{\sqrt{B}}$

where $H$ is the total height of the building and $B$ is the maximum base dimensions of the building along the considered direction of seismic force.

The 2003 ECOL edition completely eliminated these two equations. Instead, it related the period of different types of structures directly to the building height as

$T=C_{t} H^{3 / 4}$

in which, $C_{t}=0.085$ or 0.075 or 0.05 for steel MRF, concrete MRF or braced steel MRF and any other building type, respectively.

Alternatively, the value of $C_{t}$ in Eq. 3 for structures with concrete or masonry shear walls may be taken as:

$C_{t}=0.075 / \sqrt{A_{c}}$

with $A_{c}=\sum A_{i}\left(0.2+\left(L_{w i} / H\right)\right)^{2}$

in which;

$A_{c}$ is the combined effective area of shear walls in the first story.

$A_{i}$ is the effective cross sectional area of shear walls in the first story.

$L_{w i}$ is the length of shear wall $i$ in the first story.

Other methods were also allowed. It was found [16] that the dominator $C_{t}$ when calculated from Eqs. 4 and 5 results in drastic variation in the results due to changing the ratio or number of shear walls and also this equation extremely overestimates the period value. It was also found that the value of $T$ obtained from computer modal analysis of bare frames without taking the effect of infill walls is overestimated.

The 2008 ECOL edition continue to use Eq. 3 while it eliminated the second alternative used to calculate $C_{t}$ from Eqs. 4 and 5. Also, this edition allowed the use of computer modal analysis to get $T$ but the obtained value is now restricted to 1.2 of the value calculated from Eq. 3.

\subsection{Response Reduction Factor}

Seismic forces are reduced when structural response goes into the inelastic range. This is an important feature in enabling structures to resist strong earthquake shaking, provided of course that the structure has the capacity to deform inelastically through 
several load reversals without a significant loss of strength. The 2003 and 2008 ECOL incorporates this recognition by including a force modification factor $R$ used in the construction of the design response spectrum. Thus, the structure could be designed according to seismic loads less than that is specified by the elastic response spectrum due to incorporating this factor. This factor is varying from 2.0 to 7.0 according to both the lateral load resisting system and the required degree of ductility. For MRF this factor takes the values of 5.0 and 7.0 for limited and sufficient ductility, respectively, while for dual SW-MRF buildings it is either 5.0 or 6.0 for the prementioned ductility levels, respectively.

The corresponding utilized factor in the 1993 edition is called structural system factor $(K)$ and is applied directly in base shear equation. A reference value of 1.0 is specified for dual system while a reduction in base shear of 0.8 and 0.67 could be done for unductile and ductile MRF, respectively.

\subsection{Importance Factor}

The seismic protection level anticipated for a structure always depends on the degree of importance it carry. All versions of ECOL uses a basic value of 1.0 for ordinary structures. The 1993 edition specifies only another value of 1.25 for buildings whose integrity during earthquakes is of vital importance for civil protection. The 2003 or 2008 editions still keep the value of 1.0 for ordinary buildings while increasing the value assigned to vital structures to 1.4. An innovated value of 1.2 is assigned to building whose their seismic resistance during earthquakes is of importance in view of the consequences associated with a collapse, e.g. schools, assembly halls, cultural institutions etc. Buildings of minor importance, e.g. agricultural buildings are assigned an importance factor of 0.8 .

\subsection{Weight of Structure}

As the base shear is always related to the weight of the structure, the later is very important to be well identified. The weight of structure to be used in the base shear formulas was the deal load of the structure for buildings with live load less than 500 $\mathrm{Kg} / \mathrm{m}^{2}$ and for structures with higher live loads, half of the live load is to be considered in addition to the dead load. This concept was changed in the 2003 edition. In addition to the dead load a fraction of live load to be considered depending on the type of building. This fraction is 1.0 for silos, water tanks, libraries, garages, etc., and is equal to 0.5 for public buildings as schools, theatres, markets and etc. The 2008 edition continues to use these rules and added a factor of 0.25 for dwellings.

\subsection{Treatment of Irregularity}

The only definition of irregularity in the 1993 ECOL considered that regular structural system as the system at which the vertical construction items extends to the foundation without sudden change in stiffness. The concept of irregularity was more precisely treated in the 2003 or 2008 ECOL editions which have the same provisos. Firstly, the analysis type, whether plan or spatial, and the type of spectrum analysis, whether simplified or multi modal, are determined now according to the regularity of the structure in plan and elevation. Then, detailed provisions are presented to define separately the criteria for regularity in plan and elevation. 


\subsection{Modal Response Spectrum and Dynamic Analysis Requirements}

Equivalent static load method ESL was the dominant method in the1993 ECOL. This edition permitted utilizing this method for regular, in shape and system, structures up to $100 \mathrm{~m}$ height and with height to width ratio not exceed 5.0. No precise definition was applied to shape regularity. Practically, this method was valid to be applicable to most buildings. The multi modal response spectrum method (multi MRS) was applicable for buildings with heights from 100 to $150 \mathrm{~m}$ and with height to width ratio higher than 5. For buildings with higher heights the dynamic method of analysis should be applied. However, as mentioned before, neither design response spectrum acceleration nor any dynamic requirements was applied. This code edition specifies that the forces obtained from the MRS should be scaled to at least $80 \%$ of the values obtained using ESL method.

The later editions of the ECOL became more stringent with the ESL method, sometimes called in these editions simplified MRS method, that multi MRS and dynamic analysis could play a very prominent role. Same treatment in the 2003 and 2008 editions is observed. In these editions the application of simplified MRS analysis is limited to regular, in plan and elevation, structures with fundamental period equal or less than either $4.0 T_{c}$ or $2.0 \mathrm{sec}$. The value of $T_{c}$ depends on the spectrum type and the soil condition. As the values of $T_{c}$ related to spectrum type 1 is either 0.3 for subsoil class D and 0.25 for other soil types, the applicability of this method will be highly restricted to structures having $T$ less than either $1.2 \mathrm{sec}$ or $1.0 \mathrm{sec}$ for the mentioned soil types, respectively. The multi MRS method is valid to be applied to all types of buildings. Conducting multi MRS analysis is now facilitated by introducing the response spectrum accelerations. Time history analysis THA is also permitted for all types of buildings ensuring that the ground motion histories should be compatible with the response spectrum specified by the code in the critical period range. Three seismic records are minimum required, and hence the maximum response of them is considered, or seven accelograms are required to consider the average of the resulting forces to be used. Unlike the previous 1993 edition, and many international codes as will be discussed later, the forces obtained from the Multi MRS analysis are not limited or scaled to those obtained using the simplified MRS method. Otherwise, the response obtained from the THA is required not to be less than $80 \%$ of those obtained using Multi MRS analysis rather than scaling them to simplified MRS analysis.

\subsection{Drift Limits}

The 1993 ECOL specifies the drift limit not to exceed $0.005 h_{s}$ in which $h_{s}$ is the interstorey height. The drift limit is increased in the later editions of the ECOL and is related to the existence and type of nonstructural elements as unreinforced masonry infills and the degree of importance of the building. Thus $d_{r} / v \leq 0.005 \mathrm{~h}$ or $0.0075 \mathrm{~h}$ or $0.01 \mathrm{~h}$ for buildings with brittle non-structural elements attached to the structure, with ductile non structural elements and with non-structural elements fixed in a way so as not to interfere with the structure, $\mathrm{h}$ is the storey height. The displacement reduction factor $(v)$ is assigned to be either 2.5 for buildings with the two higher degree of importance and 2.0 for the last lowers importance.

In closure of overviewing the significant changes between the different editions of the ECOL, and to facilitate the comparison between the 2003 and 2008 
ECOL editions, the major changes in these two editions are summarized in Table 2.

Table 2: Significant variations between 2003 and 2008 ECOL editions

\begin{tabular}{|l|l|}
\hline Item & Description \\
\hline Elastic design & $\begin{array}{l}\text { A reduction of } 1.4 \text { and } 1.28 \text { to be applied to the forces obtained using } \\
\text { either } 2008 \text { or } 2003 \text { editions, respectively to be used in elastic design. }\end{array}$ \\
\hline Seismic zones & $\begin{array}{l}\text { A new zone with } a_{g}=0.3 \mathrm{~g} \text { is appended in } 2008 \text { edition, changes in } \\
\text { seismic zones occurred to some cities. }\end{array}$ \\
\hline Effective ineria & $\begin{array}{l}I_{\text {eff }}=0.7 \text { for uncracked SW and } 0.5 \text { for cracked SW in } 2008 \text { edition, } \\
\text { while this value was fixed to } 0.35 \text { in } 2003 \text { edition. }\end{array}$ \\
\hline Live loads & A factor of 0.25 is newly assigned to the live load of dwellings. \\
\hline Period equations & $\begin{array}{l}\text { The second alternative to calculate period for SW buildings is omitted, } \\
T \text { calculated using spatial modal } \leq \text { that calculated using } 0.05 H^{3 / 4}\end{array}$ \\
\hline
\end{tabular}

\section{SEISMIC PROTECTION LEVEL DUE TO VARIANT CODE EDITIONS}

The impact of changing the seismic provisions due to the evolution in ECOL from 1993 to 2008 on the degree of seismic protection level is investigated. The seismic protection level is simply expressed in terms of normalized base shear $(V / W)$, noting that it could be affected by other aspects of design and construction. For the purpose of comparing the provisions of different code editions, the normalized base shear is calculated utilizing the ESL method. A set of different parameters are considered in this comparative investigation as seismic zone, structural resisting system, code provided period equations, and site soil conditions. The results of this investigation are illustrated in this section, noting that this investigation is carried out in the basis of ultimate loads, so the results obtained from the 1993 ECOL editions are multiplied by a factor of 1.28.

Three different cities are selected to illustrate the impact of the geographic site seismic zone. These cities, arranged in the order of increasing the seismic zone effect, are Assiut, Cairo and Hurghada. The selection of these cities arises as they represent, according to either 2003 or 2008 ECOL editions, cities with low seismicity (Assiut; $a_{g}=0.1 \mathrm{~g}$ ), medium seismicity (Cairo; $a_{g}=0.15 \mathrm{~g}$ ) and high seismicity (Hurghada; $a_{g}$ $=0.25 \mathrm{~g}$ ). Type 1 spectrum is the one specified by code to be used for the three selected cities. Relying on the 1993 ECOL edition, Assiut and Cairo were located in seismic zone II with $\mathrm{Z}=0.2$ while Hurghada were located in seismic zone III with $\mathrm{Z}=0.3$. The first investigated buildings are assumed to be ordinary types with importance factor equal 1.0. The reference soil type $\mathrm{C}$ is assigned to Assiut and Cairo while soil type $\mathrm{B}$ is assigned to Hurghada. The results of $(V / W)$ obtained for two commonly used types of RC structures, MRF and dual SW-MRF regular buildings, are illustrated in Figs. 1 and 2, respectively with horizontal axis represents the building height. The maximum considered building heights, $31.5 \mathrm{~m}$ for MRF and $52.5 \mathrm{~m}$ for SW-MRF buildings, are used so as to match the 2003 and 2008 ECOL restrictions of utilizing the simplified MRS method to building fundamental period less than $4 T_{c}$ which is $1.0 \mathrm{sec}$. The three cities Assiut, Cairo and Hurghara are assigned the following notations ASS, CAR and HUR, respectively. 
Discussing first the results obtained for the MRF buildings, it is clear, as shown in Fig. 3, that the seismic protection level SPL utilizing the 2008 ECOL edition is generally higher than that is obtained using the 1993 ECOL edition with different percentage changes. The minimum change is obtained for ASS city due to two reasons, the first reason is the downgrading of the seismicity of this city from zone 2 (out of 3 zones) in 1993 edition to zone 1 (out of 6 zones) in 2008 edition. The second reason is due to the new low seismicity of this city. Generally, the \% change almost decreases as the building height increases. The observed \% change in seismic protection level for this city, due to changing the seismic provisions, ranges, over different building heights, between $22 \%$ and $43 \%$. As the site seismic intensity increases, the \% change in SPL increases. Although the degree of seismicity of the other two cities, Cairo and Hurghada, are not changed in the different code editions, the \% change in SPL drastically increases as the site seismicity increases. While this ratio of change ranges between $84 \%$ and $115 \%$ for CAR city it highly increases to range between $118 \%$ and $147 \%$ for HUR city, noting that the site seismicity is almost the same for the two 2003 and 2008 code editions. It is worth to mention that the sudden change in the curves representing base shear is attributed to the correction factor $\lambda$.

In order to calculate the normalized base shear $V / W$ for the SW-MRF buildings shown in Fig. 4, the width of the buildings, to be used in the 1993 ECOL period equation is assumed to be equal to $20 \mathrm{~m}$. The period equation $\left(T=0.05 \mathrm{H}^{3 / 4}\right)$ is used for calculating $V / W$ using the later code editions. It is observed that the \% change in the SPL in case of SW-MRF buildings is relatively less than what is observed for the MRF buildings by a ratio up to about $35 \%$, However, there is still high extreme change in the results obtained used either 2003 or 2008 relative to the results obtained utilizing the 1993 edition. The new \% change in the SPL over the different considered heights is in the range of $2 \%$ to $28 \%$ for ASS, $53 \%$ to $92 \%$ for CAR and $82 \%$ to $121 \%$ for HUR city.

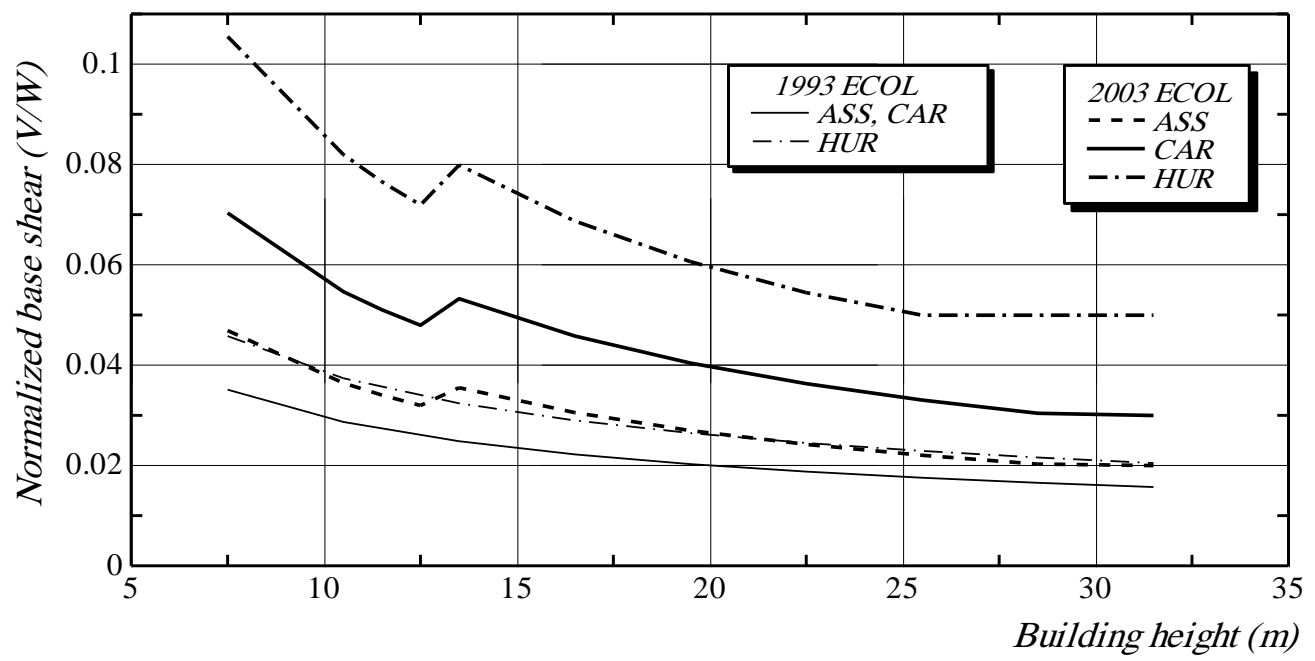

Fig. 3 : Normalized base shear calculated for different cities (MRF building) 


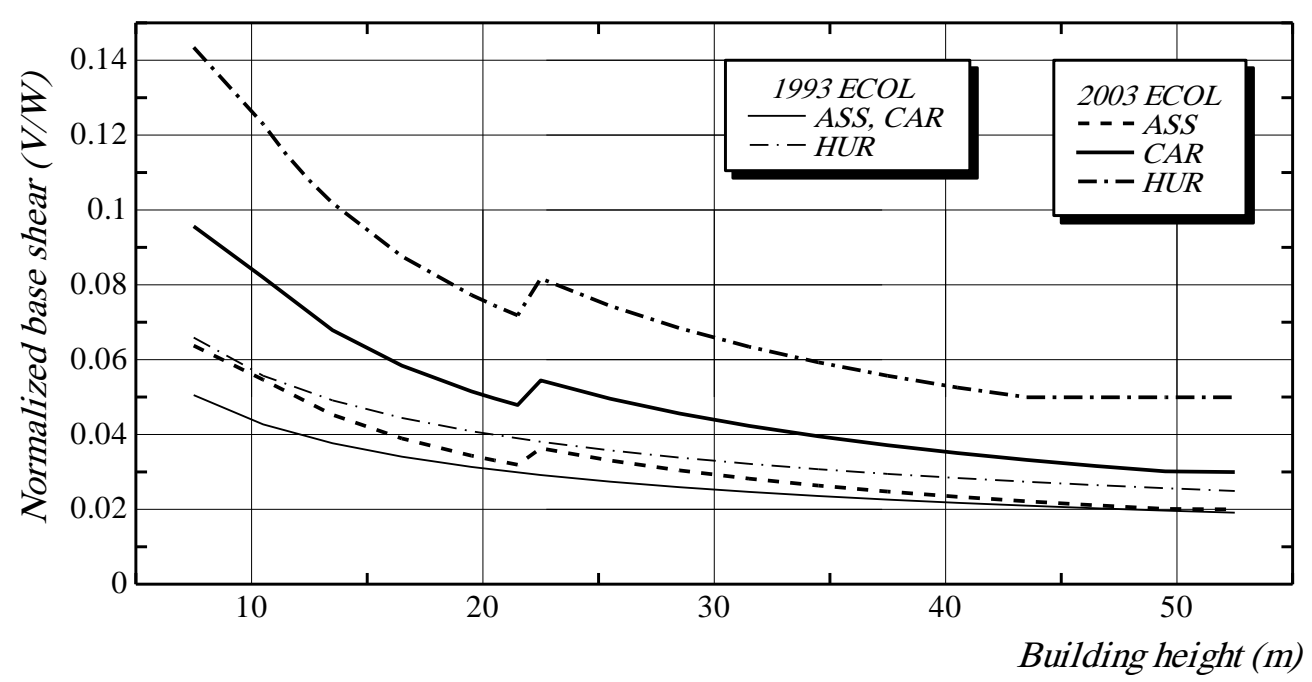

Fig. 4: Normalized base shear for different cities (SW-MRF building)

The impact of changing the code equations specified for calculating the fundamental period of SW-MRF buildings in 1993 and 2003 editions and there different parameters is investigated. The impact of the variation in these equations could be better discussed through studying the SPL provided for a coastal city that relies to spectrum type 2 as Alexandria. The reason for this selections is the second alternative of the 2003 ECOL edition for calculating the period for SW buildings, Eqs. 4 and 5 in this paper, yields high period values which require higher period limit to apply the simplified MRS method. The value of $T_{c}$ in spectrum type 2 ranges between 0.4 and 0.8 which in turn yields a increase the validity of applying the simplified MRS method to values of fundamental period ranges between 1.6 and 3.2 sec for soil types arranged from A to D, reference soil type C is assumed for Alexandria. In either 2003 or 2008 editions, Alexandria city is classified in seismic zone II (out of 6 zones) with $a_{g}=0.125 \mathrm{~g}$, while it was classified in zone III (out of 3 zones) in 1993 edition. The period equation in 1993 edition is affected by the width of building, so three different values for the building width $\mathrm{B}$ are investigated which are 10,20 and $30 \mathrm{~m}$. The 2003 edition assigns the nominator $\left(r=L_{w} / H\right)$ to the period equation assigned to SW buildings, values of $r=0.3$ and 0.4 are considered for this type of soil, so that the resulting period rely to the code limitations of using simplified MRS. Firstly, discussing the effect of equation parameters, it can be observed, as shown in Fig. 5 that the values of seismic protection level increases with increasing either $B$ or $r$ when utilizing 1993 and 2003 ECOL editions, respectively. The maximum \% change in $V / W$ due to changing $B$, in reference to $20 \mathrm{~m}$ width, is $+11.1 \%$ and $-15.9 \%$ for $B=30$ and $20 \mathrm{~m}$, respectively. The variation in $r$ ratio from 0.3 to 0.4 results in $\%$ change of about $+24 \%$. The impact of changing the whole period equation in the different code editions is well realized from the results obtained from 2003 and 2008 editions while all other parameters affecting the calculated base shear are identical in these two versions. There is extreme variation in the results obtained using these two versions, the $\%$ change is in a range between $+50.9 \%$ to $+102.4 \%$. 
Comparing between the results obtained using 1993 and 2008 editions, noting that the results are affected by parameters other than period, it is found that the $\%$ change in SPL is in range of $-19.9 \%$ to $+56.5 \%$ depding on the building height.

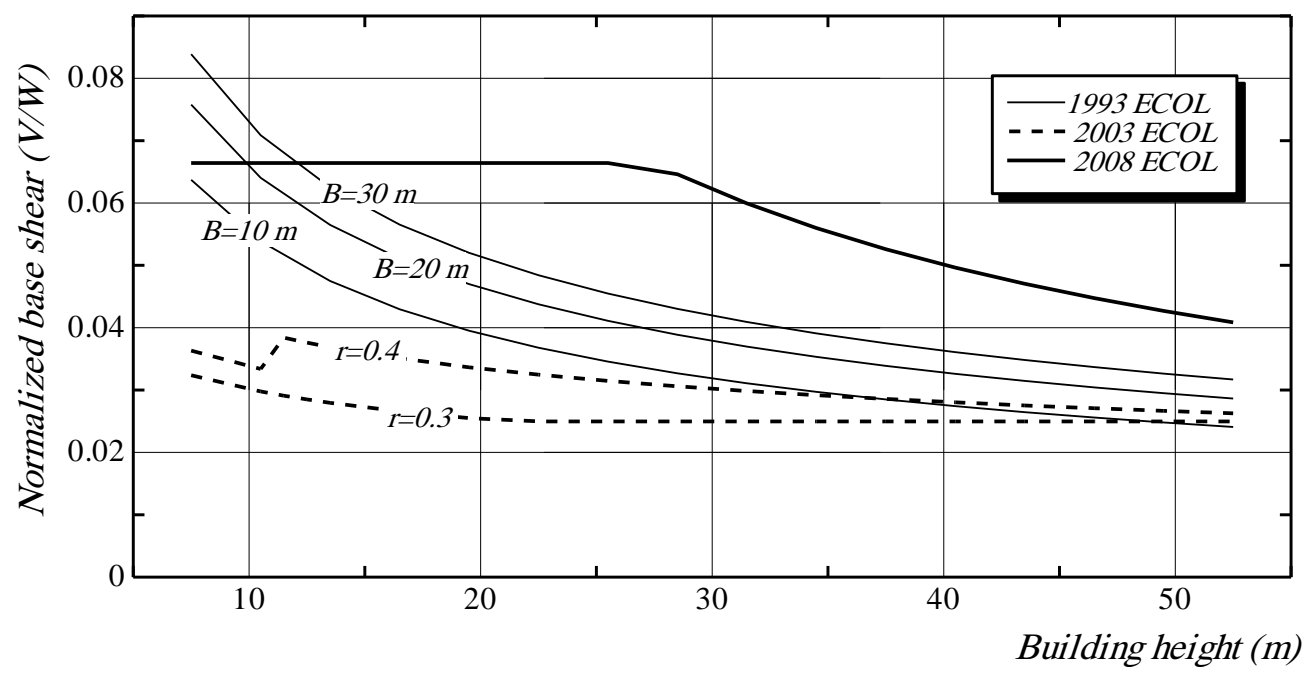

Fig. 5 : Effect of different period equations on the normalized base shear (Alex. City)

This section ends with discussing the impact of site soil conditions. It is mandatory, as mentioned before, in either 2003 or 2008 ECOL editions to carry out soil experiments to determine specifically the site subsoil type for buildings with high importance or located in high seismic zone. The soil type is determined according to actual records of shear wave velocity for a depth of at least $30 \mathrm{~m}$, if not available the penetration test could be carried out. The impact of soil is investigated for high importance buildings located in Cairo on different soil types relying on both 1993 and 2003 ECOL editions as illustrated in Fig. 6.

The soil type has a minor effect on the SPL in 1993 ECOL edition as its effect is directly influencing the base shear equation by a factor of $1,1.15$ or 1.3 for the different soil types. So, the $\%$ change in the $V / W$, related to reference soil with $S=1.15$, does not exceed $\pm 13 \%$. In the later code editions, the subsoil condition affects the construction of the response spectrum and hence a high variation in the results and over height occurs. In more details and relating the results to the reference soil type $\mathrm{C}$, it is found that unlike soil type B which results in values close to those obtained for soil type with maximum $\%$ change does not exceed $10 \%$ there is extreme variation in results for the other two subsoil types. The $\%$ change in $V / W$ could reach up to +44 and $-33 \%$ for soil types $\mathrm{A}$ and $\mathrm{D}$, respectively.

Carrying out a comparison between the seismic protection level obtained utilizing the provisions of 1993 and 2005 ECOL editions, it is observed that the magnification of soil increases as the soil flexibility increases. While the $\%$ change in seismic protection level ranges between $41 \%$ to $102 \%$ for buildings found on rock soil, it largely increases to reach a range of about $115 \%$ to $166 \%$ for loose to medium cohesion soil. 


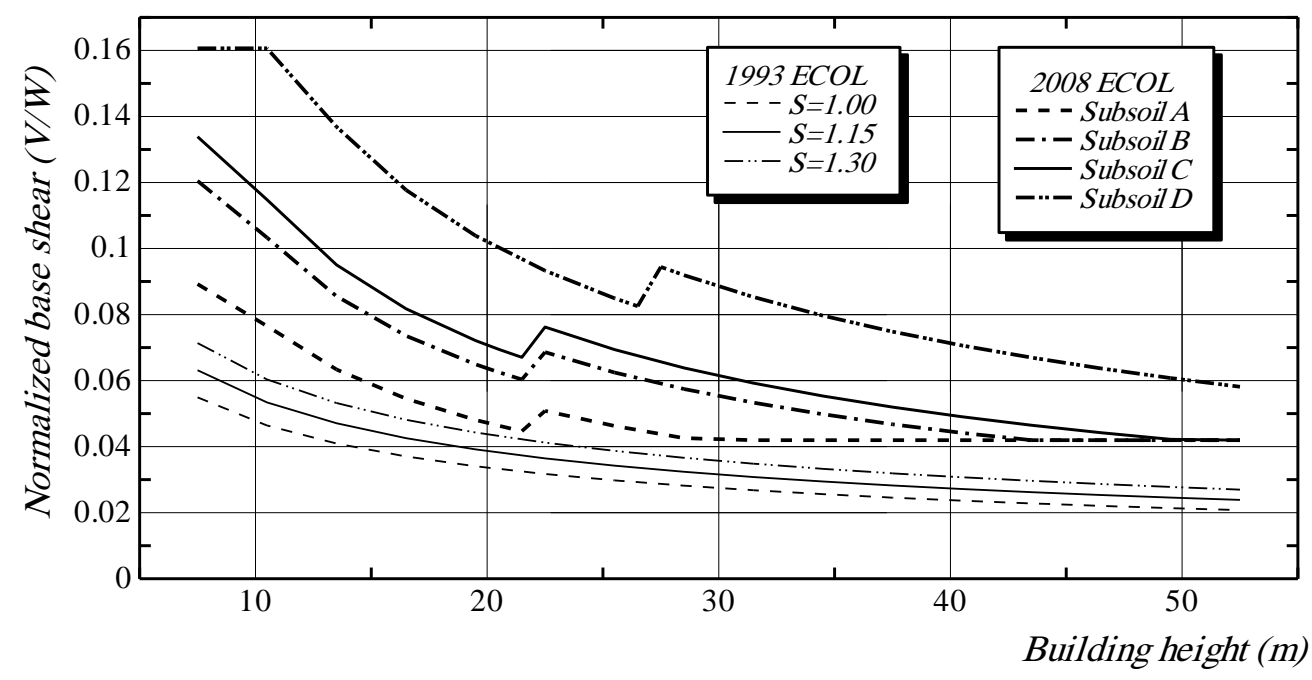

Fig. 6 : Effect of site soil conditions on normalized base shear (Cairo city)

\section{VERIFYING DIFFERENT ANALYSIS METHODS IN 2008 ECOL}

The seismic provisions in the ECOL, in all its editions, specify three different methods to get the design base shear which are modal response spectrum analysis MRS, either simplified or multi-modal, and the dynamic time history analysis. However, the limitations of using each of these methods vary between the 1993 and later two editions. Nowadays, structural analysis software capable of conducting a multi MRS or linear dynamic analysis are widely available and designers are becoming increasingly comfortable in using them. According to the later editions of ECOL multi MRS and THA are valid to be utilized for all types of structures and in many cases simplified MRS can also be used. Thus, the main objective of this section is to compare the SPL obtained using either of the three mentioned method and also to verify type 1 response spectrum adopted to all regions in Egypt with seven real ground excitations match the code proposed conditions.

\subsection{Buildings used in Computer Base Analysis}

In order to carry out either multi-MRS or THA two types of regular buildings, MRF and SW-MRF are used. Fig. 7 depicts example SW-MRF, The MRF building has same plan features while replacing the shear walls with columns. The buildings are square with typical bay dimension of $5.0 \mathrm{~m}$. Different building heights represented by the number of floors are considered, 3, 6, 9, 12, 15 and 17 floor buildings are analyzed. The first floor is always equal to $4.0 \mathrm{~m}$, while the height of the typical remaining floors are $3.0 \mathrm{~m}$. The column sections are varying according to the height of building.

The effective total lengths of shear walls in the first storey in each orthogonal direction $\left(L_{w}\right)$ is seismically designed. This ratio $\left(L_{w} / H\right)$ is 0.20 for each orthogonal direction, SW thickness is $0.2 \mathrm{~m}$. The compressive strength of used concrete is 25.0 $\mathrm{MPa}$ while the used steel is high tensile with yield strength of $400.0 \mathrm{MPa}$. The analysis is carried out using two software packages ETABS [21] and SAP 2000 [22]. 


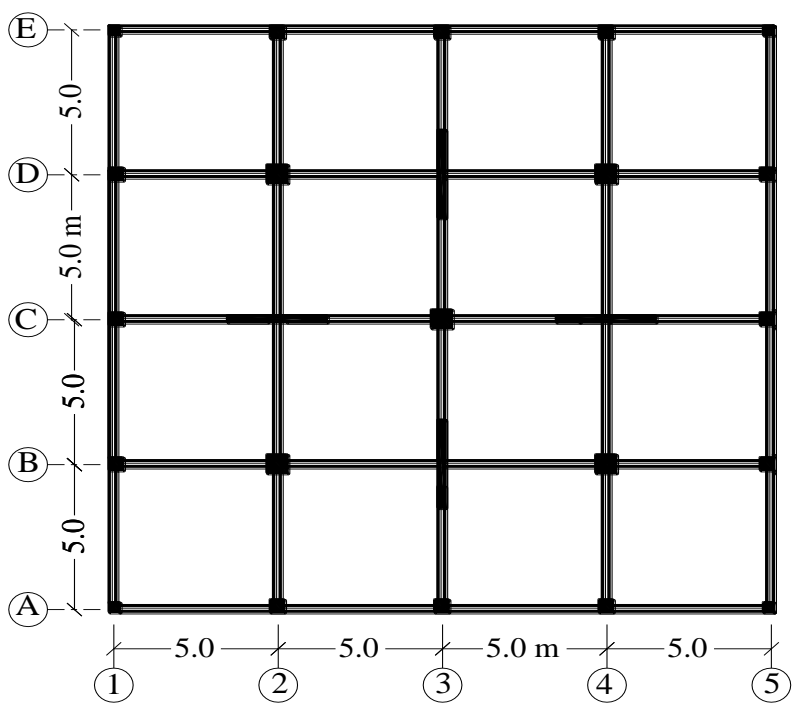

Fig. 7 : Plan of example SW-MRF regular building

\subsection{Applied Ground Excitations}

Seven different ground excitations, shock different five countries, are selected to match the seismicity of Cairo with soil type $\mathrm{C}$. Six of these excitations naturally have maximum scaled spectrum acceleration $\left(2.5 a_{g} S\right)$ close to the one calculated for Cairo. The seventh one, Aqba earthquake which shook Egypt in 1998, is scaled to match the seismic requirements for Cairo city. The spectrum acceleration of these quakes along with the used notations are shown in Fig. 8.

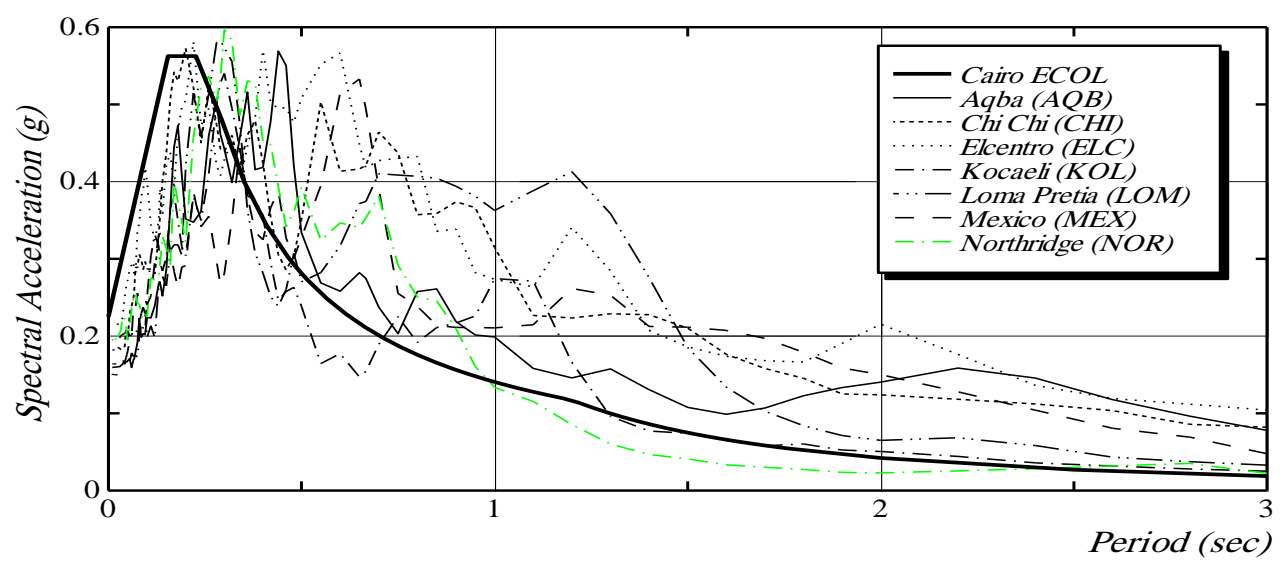

Fig. 8 : Response spectral acceleration of used excitations versus code spectra

\subsection{Results and Discussions}

The results of multi MRS and dynamic THA, using the indicated seven ground excitations, in comparison with those obtained using the simplified MRS for both MRF 
and SW-MRF buildings are illustrated in Figs 9 and 10, respectively. Before discussing the results it is worth to mention that the elastic response spectrum obtained from the different indicated excitations and used for THA are modified to account for the response modification factor. Also, the obtained results from this method, THA, are scaled to be ultimate loads using a factor of 1.4. In case of MRF buildings, the results obtained using the simplified MRS are valid up to height equal to about $32.5 \mathrm{~m}$ according to code limitations which restricts the utilization of this method to $4 T_{c}$, however, for the purpose of comparison, the curve is virtually extended over the whole considered height. As seven excitations are considered in the THA, then the average response of these excitations could be considered, this average is illustrated using the dash line.

Firstly, discussing the results obtained for the MRF, it is clear that, generally, the highest SPL is obtained in the order of, THA, simplified MRS and at last the multi MRS analysis. The SPL obtained utilizing the multi-MRS methods is much less than those obtained using the simplified MRS method over the whole considered building heights. The $\%$ change, related to the simplified MRS method is in the range of $-35.6 \%$ to $-48.8 \%$. The average results obtained from THA are higher than those obtained using simplified MRS method in the height range that compel to the limitation of using the later method. The $\%$ change ranges between $+21.8 \%$ and $-39.7 \%$. In the rest of height range the $\%$ change ranges between $+24.6 \%$ and $-30.8 \%$. It is observed that the results of scaled Aqaba quake, the only one of the considered excitations that shook Egypt are very close to the results of the simplified MRS method. It is worth to mention that, in contrary to the code expectation which limits the results of the THA to the multi MRS analysis, the results of the former method is higher than the later one be a $\%$ change in the range of $+11.4 \%$ to $+138.6 \%$.

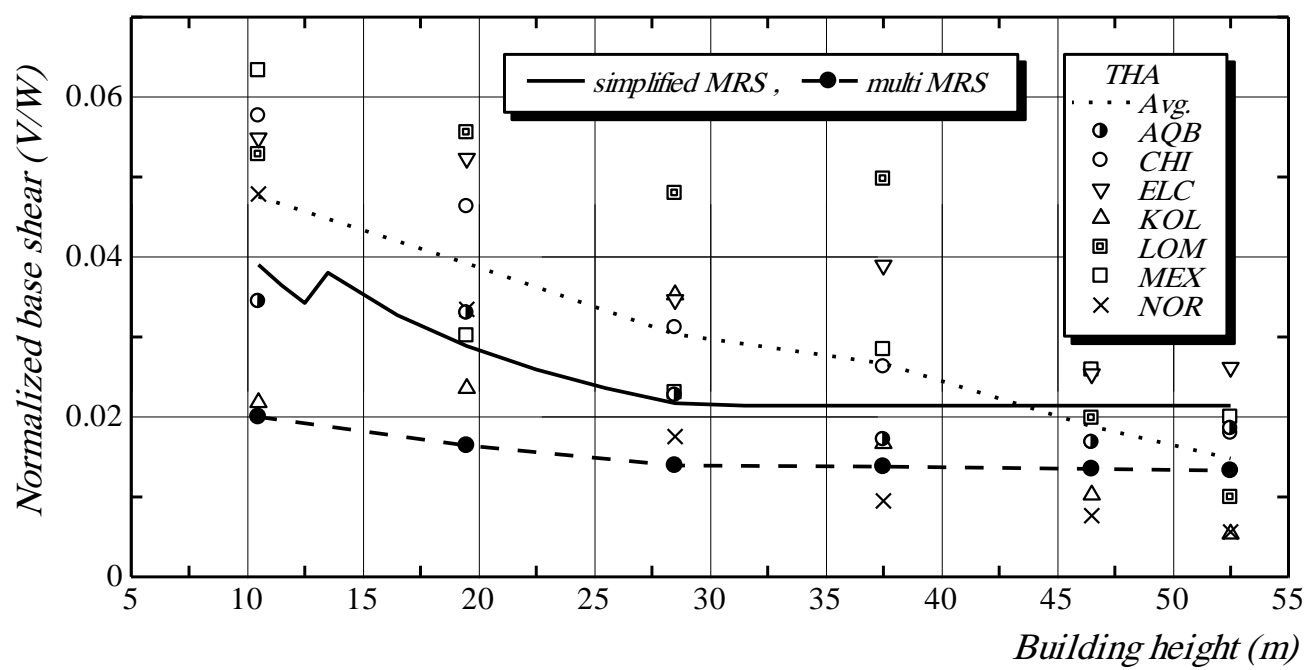

Fig. 9 : Normalized base shear due to different analysis methods (MRF building)

The last presented investigation is carried out for SW-MRF buildings, similar observations are obtained except some differences which is to be discussed. Unlike the 
whole considered height range, the SPL obtained from simplified MRS is higher than the average of THA method. The change is attributed to that at this height the code calculated period for SW-MRF building is 0.29 while it was 0.43 for MRF with same height and due to the nature of the used spectrum the obtained base shear is amplified at short periods. Thus, except this height the \% change in the SPL between the average THA and simplified MRS is in the range of $+26.1 \%$ and $3.3 \%$. The $\%$ change in SPL between multi MRS and simplified MRS is higher than what was obtained for MRF buildings and of a range between $-36.3 \%$ and $-58.7 \%$. Regarding the $\%$ change in results between average THA and MRS analysis is still high and in the range of $+62.1 \%$ and $+134.0 \%$. In closing, of these observations, the scaled Aqaba excitation is still yields the closest results to the simplified MRS method.

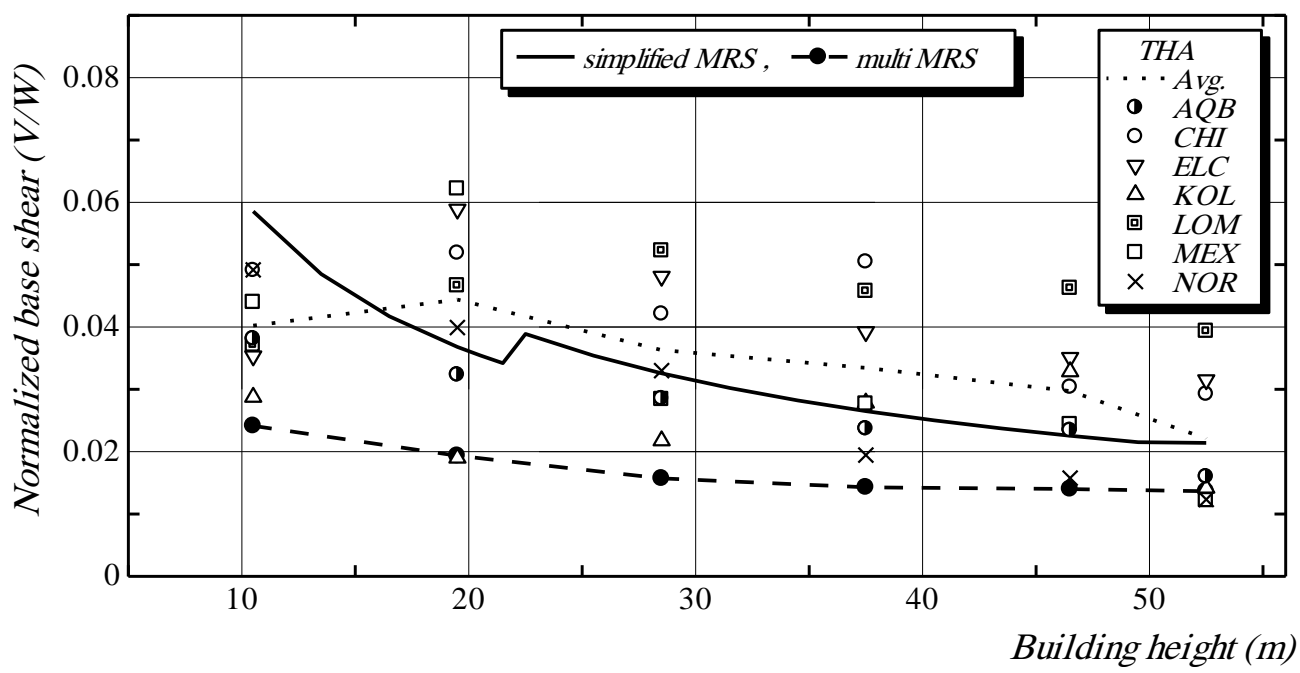

Fig. 10 : Normalized base shear due to different analysis methods (SW-MRF building)

As the 2008 ECOL considers the multi MRS analysis method as basis for design that is valid to all type of structure an due to the extremely low response obtained using this methods in accordance with the other two methods an attempt is carried out to enhance the response obtained using this method. The reason for this highly underestimated behavior, at least in comparison with the simplified MRS, can be concluded in the long period obtained from modal analysis due to analyzing the structure as bare frame without considering the effect of masonry infill walls. This long period is supported by the rapid change in spectral reduction ductility factor which, in the assumed type 1 spectrum has high influence, to yield such extremely low response. In this relevance, most seismic codes limit the results obtained using the multi MRS to those obtained using simplified MRS. The 2008 ECOL does not provide such limitation although it was provided by the 1993 ECOL. The later edition, as mentioned before, limit the forces obtained from the multi MRS to a minimum of $80 \%$ those obtained from the simplified MRS. Another way to enhance the results is the consideration of the effect of masonry infill walls. This is carried out for both MRF and SW-MRF buildings. The infill walls are assumed to occupy $60 \%$ of the total number of 
panels in every orthogonal direction. Masonry infill walls with commonly used $0.12 \mathrm{~m}$ thickness are used, modulus of elasticity of infill walls is assumed to be $E=5 \mathrm{GPa}$. Two models of infill walls are considered, the first is solid walls without any infills while the second considers central openings in the walls results in equivalent wall width of $60 \%$ the solid one. The infill walls are modeled using the methodology of equivalent strut method [23], the effect of the openings in masonry infill walls is considered relying on [24].

The results of $V / W$ for the MRF buildings are illustrated in Fig. 11. It can be concluded that the consideration of infill walls has a high influence on enhancing the SPL obtained from the multi MRS method. Comparing the results of the later method with the simplified MRS in its applicability height range (up to about $32.5 \mathrm{~m}$ ) it is found that the consideration of infill walls has high influence in enhancing the SPL especially for lower building heights. The \% change in \% SPL, relative to simplified MRS, does not exceed $-10.1 \%$ for solid wall model and $-20.3 \%$ for walls with opening model. Beyond this height limitation and as the building height increases the influence of infill walls vanishes. This is evident as at higher values of period the spectrum plateau is almost horizontal.

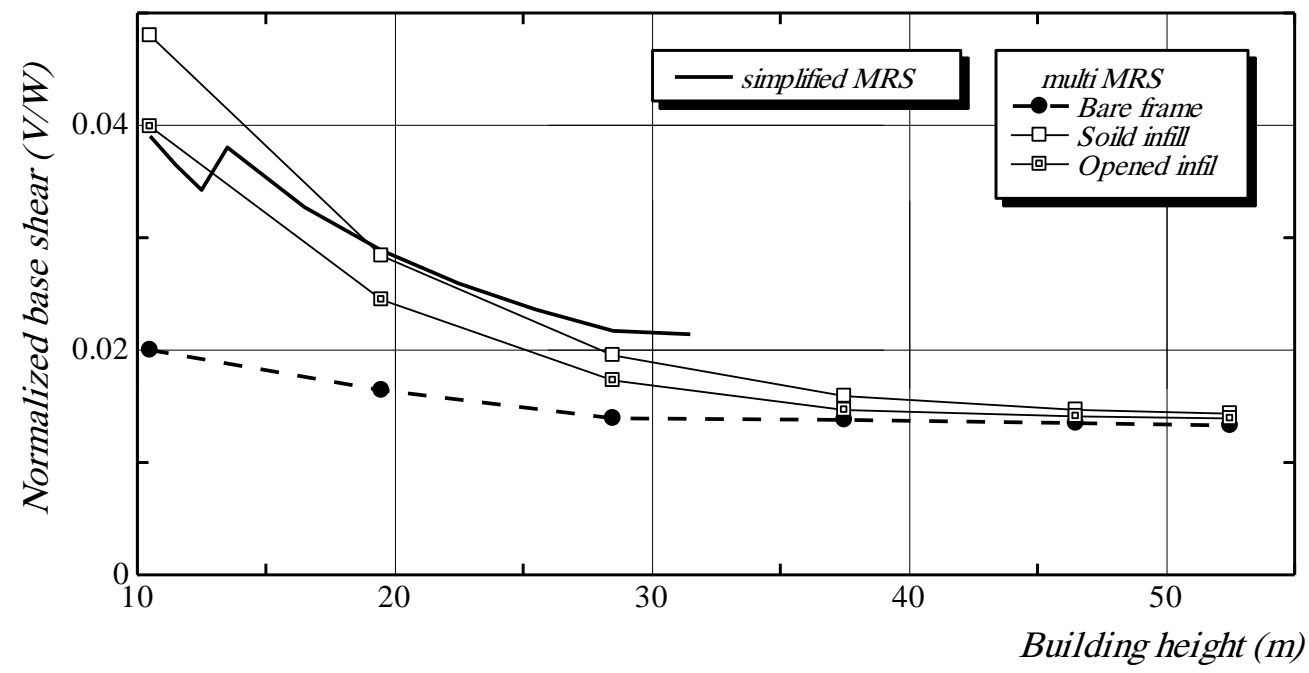

Fig. 11 : Effect of masonry infill wall consideration (MRF building)

Similar observations could be drawn out for SW-MRF buildings, but with different $\%$ change, the results of this structural system are depicted in Fig. 12. It could also be confirmed that the consideration of infill walls in the structural model is most influential for lower building heights. The obtained \% change in SPL, relative to the simplified MRS, is in the range of $-18.5 \%$ to $-34.7 \%$ for the soil wall model and in the range of $-28.6 \%$ to $-40.1 \%$. Noting that the obtained values are for specific considered parameters of infill walls, different $\%$ change in the results could be obtained due to changing the infill parameters. 


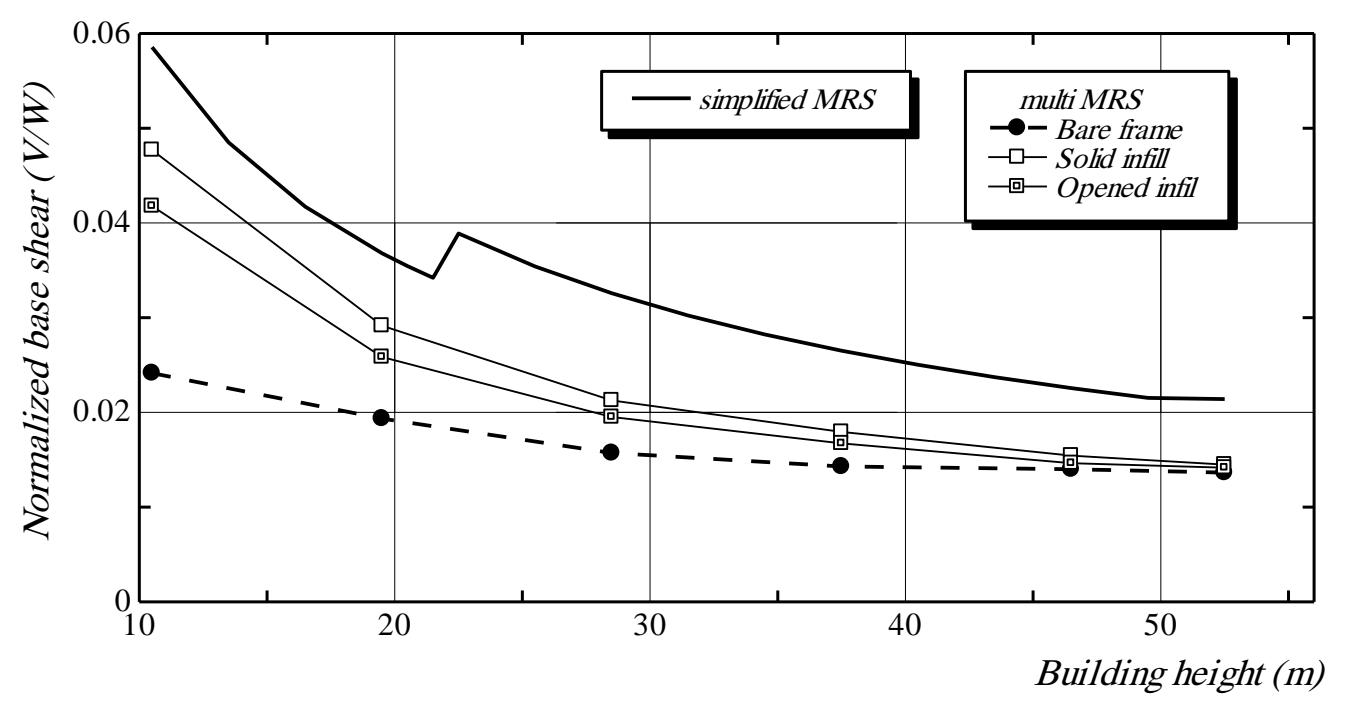

Fig. 12: Effect of masonry infill wall consideration (SW-MRF building)

\section{SEISMIC PROTECTION LEVEL IN ECOL VERSUS OTHER CODES}

To verify the seismic protection level provided by the 2008 ECOL versus the results obtained from some different international codes, three seismic codes are selected. These codes include Eurocode- 8 , which is the basic referenced code to ECOL, the famous $U B C 97$ and Finally the recently renewed National Building Code of Canada.

For the sake of carrying out a rational comparison between these codes versus the $2008 E C O L$, results obtained for buildings in Cairo city found on soil type $\mathrm{C}$ are compared with those for same building types found on same soil conditions and located in cities with seismicity similar to Cairo. Doing so, a city with zone factor $Z$ $=0.15$ is selected to represent UBC 97 code while Kamloops city which is remarked by $\mathrm{PGA}=0.14 \mathrm{~g}$ is selected to represent the $N B C C$. Typical conditions to Cairo city are available in the Eurocode-8. The elastic response spectrum, which is constructed in regardless of the over strength factor, for the selected cities are illustrated in Fig. 13.

In this figure, type 2 spectrum is added for the sake of illustration. Some notes could be highlighted for this figure. These notes include the high proximity in the values of maximum spectrum acceleration between $E C O L$ with either spectrum types and the $U B C-97$. There is high correlation between the spectrum specified in type 2 $E C O L$ spectrum and $U B C-97$. Also the maximum spectrum acceleration specified by the $N B C C$ is much less than all other code spectrum. Finally, the beginning of the descending spectrum curve is close between type $1 E C O L$ spectrum and the $N B C C$ and there is somehow correlation in the spectrum specified for the later two codes.

To get the design response spectrum from the elastic response one, all ordinates of spectral accelerations are divided by a factor used to incorporate for the inelastic response expected for the structure to the design earthquake. This factor is called response modification or force reduction factor $(R)$ in 2008 ECOL, behavior 
factor in Eurocode-8 $(q)$, structural system coefficient $(R)$ in $U B C 97$ and overstrength and force modification factors $\left(R_{o} R_{d}\right)$ in $N B C C$. This factor depends mainly on the structural force resisting system (SFRS) and its proposed degree of ductility. Summary of values for response modification factor for MRF and SW-MRF buildings is shown in Table 3. A particular emphasis is to be carried out in this section to investigate the impact of this factor. It is worth to mention that this factor represents a major significant change between the seismic provisions in 2008 ECOL and Eurocode-8.

Table 3: Summary of response modification factor for MRF and SW-MRF buildings

\begin{tabular}{|l|c|c|c|c|c|c|}
\hline Structure system & \multicolumn{3}{|c|}{ MRF } & \multicolumn{3}{c|}{ SW-MRF } \\
\hline Ductility level & Low & Medium & High & Low & Medium & High \\
\hline ECOL & 5.0 & - & 7.0 & 5.0 & - & 6.0 \\
\hline Eurocode-8 & - & $3.3-3.9$ & $4.95-5.85$ & - & $1.8-3.6$ & $2.7-5.4$ \\
\hline UBC 97 & 3.5 & 5.5 & 8.5 & - & 6.5 & 8.5 \\
\hline NBCC & 1.95 & 3.5 & 6.8 & 1.95 & 2.8 & 5.6 \\
\hline
\end{tabular}

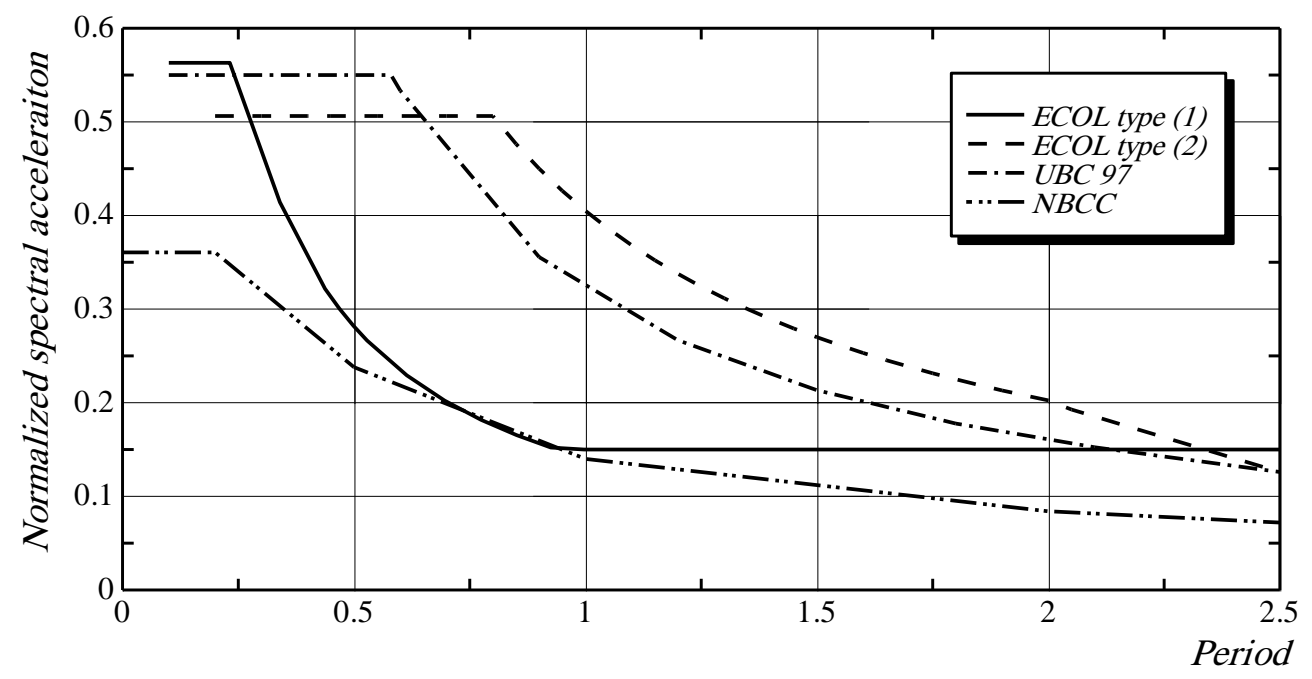

Fig. 13 : Normalized spectral acceleration for specified cities in different codes

As they need high attention in design, practically constructed in Egypt and to save space, the results obtained for structures with first lower degree of ductility are discussed. Results for any other degree of ductility can be easily obtained by scaling the results to the required degree of ductility. The obtained $V / W$ are calculated using both simplified and multi MRS analysis. The computer based results of the later method are obtained using the structures previously described in subsection 4.1.

The results obtained for the MRF buildings using the different considered seismic codes are shown in Fig. 14. It can be noted that the obtained results of the $V / W$ 
can be arranged in the order, from higher to lower results, according the following codes, $U B C$ 97, NBCC, Eurocode- 8 and at last the ECOL. There is extreme variation in the results obtained from $U B C 97$ and $N B C C$, using either considered method of analysis, in comparison with the results obtained from the ECOL. The \% change is higher for the results obtained utilizing the simplified MRS method. The $\%$ variation in SPL, relative to the ECOL, ranges between $108.6 \%$ to $225.08 \%$ and from $97.9 \%$ to $154.55 \%$ utilizing $U B C 97$ and $N B C C$, respectively. Due to the fact that identical elastic spectrum is assigned for both ECOL and Eurocode-8, the variation in results is attributed the influence of the force reduction factor. Thus the results obtained from Eurocode- 8 are higher than those obtained using ECOL be a ratio of about $28 \%$. The results obtained utilizing the simplified MRS method are braced by those obtained using the computer bases multi MRS method. The last mentioned observations are valid but with different percentage ratios. The new $\%$ ratios range between $66.6 \%$ to $232.2 \%$ for $U B C 97$ and from $54.7 \%$ to $158.1 \%$ for the Eurocode-8. These results indicate that the upper limit of $\%$ change is close between the two method and that the $\%$ change in the SPL is inversely relative to the building height.

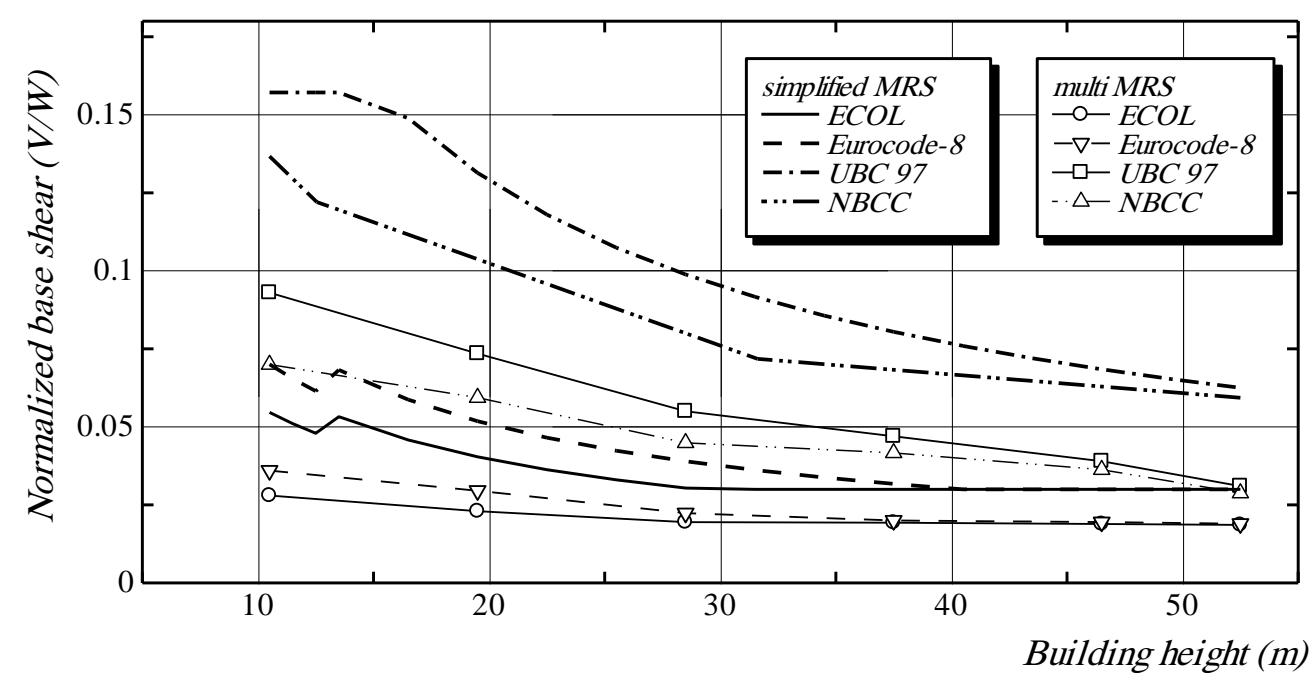

Fig. 14 : Normalized base shear according to different codes (MRF building)

The dual SW-MRF system is also investigated for the same lower ductility level. The code specified response reduction factors are 5.0, 6.5 and 1.95 for ECOL, $U B C 97$ and NBCC, respectively. This factor for dual systems, in the Eurocode-8, depends on the length of the shear walls and the building height. For the investigated building heights and the specified shear wall lengths, this factor decreases from 2.2 to 1.8 as the height increases from 10.5 to $52.5 \mathrm{~m}$. The results of both used methods utilizing the different considered codes are illustrated in Fig. 15. It can be observed that the highest \% change in the results are obtained for the NBCC and Eurocode- 8 which over most studied heights reveal close results. For these two codes, $\%$ change, relative to ECOL, range between $127.2 \%$ to $177.8 \%$ and from $103.9 \%$ to $154.9 \%$ for the $N B C C$. The first ductility level in UBC 97 in case of dual SW-MRF buildings is shear 
walls with intermediate MRF ductility with $R$ coefficient of 6.5 . Thus, $\%$ change in results between $U B C 97$ and $E C O L$, decreases relative to the observed results of MRF buildings, to a range less than $75.0 \%$. The \% change in the SPL obtained from the $E C O L$ versus other codes are well matched to those obtained using the simplified MRS method with maximum difference less than $6.0 \%$.

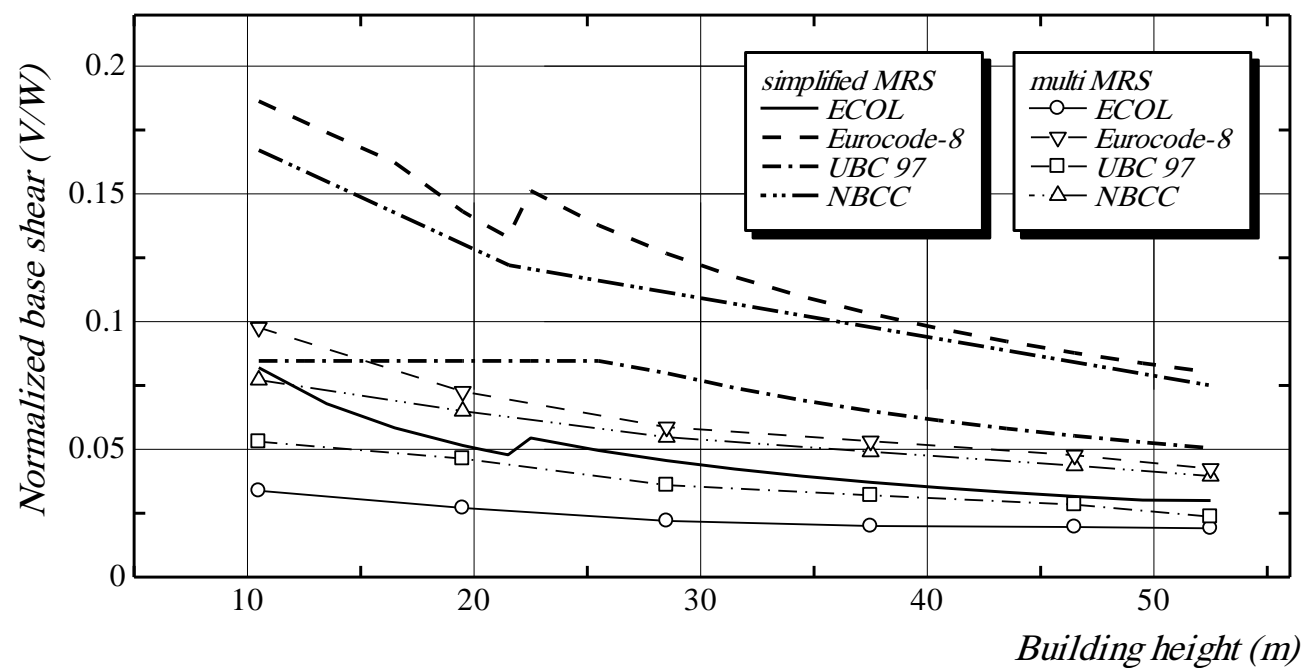

Fig. 15 : Normalized base shear according to different codes (SW-MRF building)

In closing of this section, the crucial effect of the response factor can be also illustrated through studying the change in SPL of irregular MRF structures due to utilizing ECOL and Eurocode-8. Another motive for carrying out such investigation is to verify the results obtained using multi MRS for irregular structures. As mentioned before the 2008 ECOL restricts the application of simplified MRS analysis to irregular structures, hence utilizing either multi MRS or THA is mandatory.

The investigated building, which is shown in Fig. 16, is irregular in plan according to the irregularity criteria specified by both considered codes due to the shown extension. The typical bay dimension is $5.0 \mathrm{~m}$ in each orthogonal direction. Irregularity is also applied in the vertical dimension due to setback of the extended part in the last two floors. Different building heights are considered and represented by the total number of floors. The considered total number of floors is $3,6,9,12,15$ and 17 floors.

As the same elastic spectrum is assumed for both two codes, the only difference in results will arise from assigning different response modification factors. While the ECOL does not differentiate in the response reduction factor between regular and irregular structures, Eurocode- 8 specifies a reduction of $20 \%$ in the response reduction factor in case of irregular buildings rather than regular buildings. So the resulting factor is 5.0 for ECOL and 3.12 for Eurocode-8. A multi MRS analysis is carried out, the results are shown in Fig. 17. It is clear that the variation in the value of response reduction factor between the two codes yields a $\%$ change in the results, relative to the ECOL, up to $60 \%$ for 3 floor buildings. The $\%$ change decreases as the building height increases to reach lower limit of $6 \%$. 


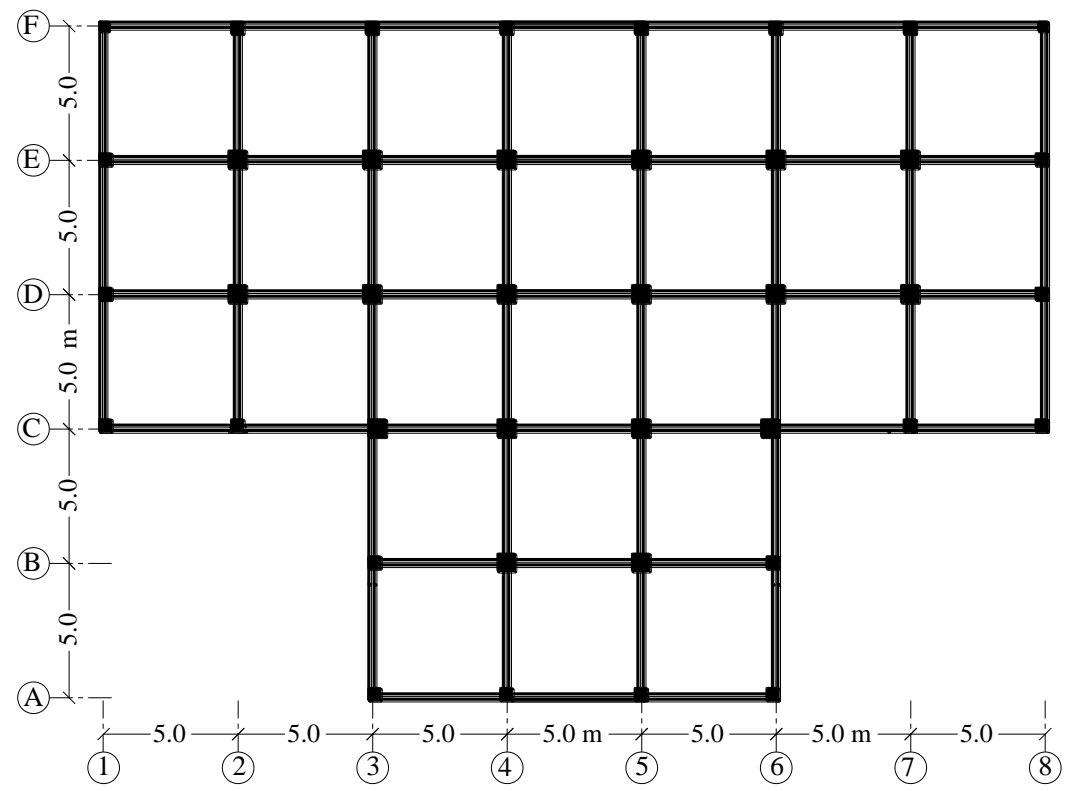

Fig. 16 : Plan of irregular MRF building

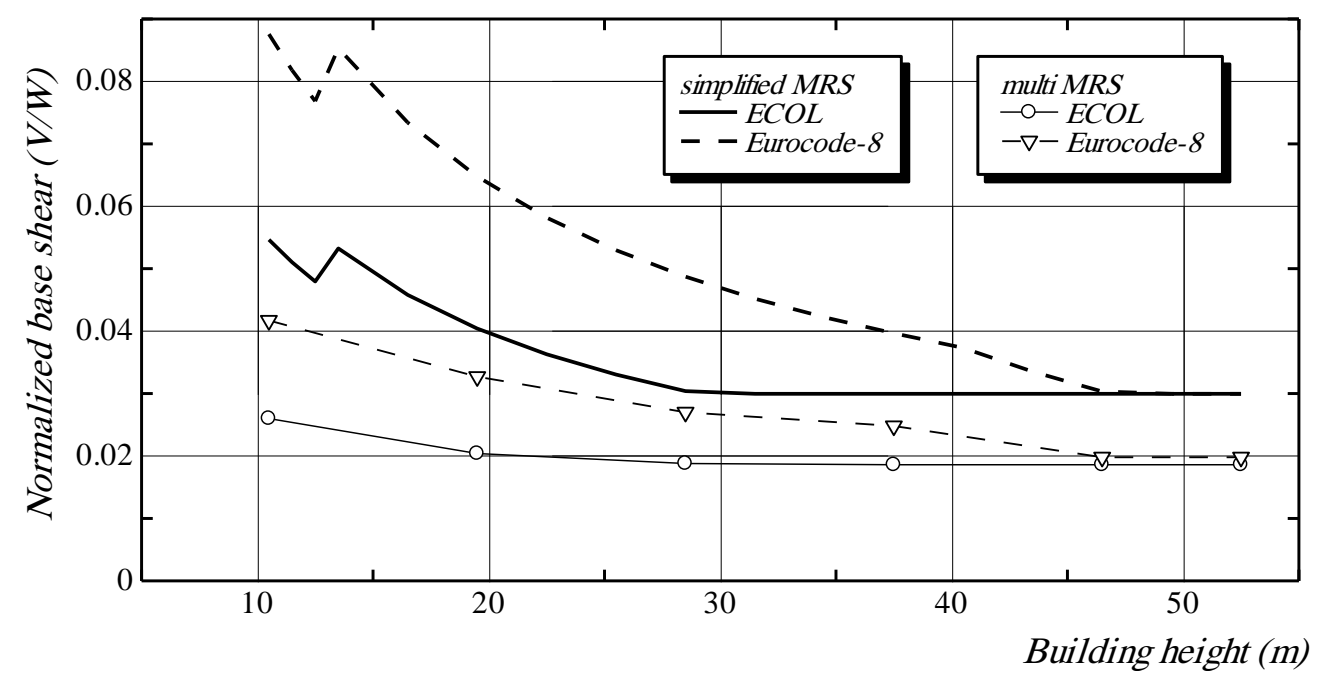

Fig. 17 : Effect of response modification factor on irregular buildings

\section{CONCLUSIONS}

The significant changes in seismic provisions presented in different editions of the ECOL through 1993 to 2008 editions are briefly described and analyzed. The impact of these changes on the seismic protection level of structure SPL, represented by the normalized base shear, is investigated. Comparative numerical computer based multi MRS and THA using the code specified spectrum and seven deliberate earthquakes is 
carried out. The results of this investigation are compared with the base shear calculated using the simplified MRS to assess and verify the impact of utilizing any of these methods and come up with required response enhancements. Finally, a particular emphasis is paid to discuss the influence of response modification factor introduced in the 2008 ECOL in comparison with different national codes. Relying on the investigations and discussions presented in this study, the following conclusions may be drawn out.

- The major evolution in seismic provisions from 1993 ECOL to the later editions was remarked by the adoption of PGA depending response spectrum, adapted by factors to reflect the inelastic capacity of structures, instead of static approaches directly relating base shear to some parameters. While the equivalent static method was widely accepted by the earlier edition it now faces many restrictions leading to the mandatory application of either multi MRS or THA. In fact changes in almost all seismic provision aspects are observed between 1993 ECOL edition and the latter one. However, specific, yet influential, changes are remarkable between 2003 and 2008 editions.

- The applied changes between the 1993 edition and later ones have excessive impact on the SPL. Generally, for most studied cases with different parameters, the new 2008 code provisions yield higher SPL. The \% change in normalized base shear between 1993 and 2008 editions increases as the site seismicity increases and usually decreases as the building height increases, this \% change could excessively reach values higher than $100 \%$. The code provided equations to calculate the fundamental period of shear wall buildings play crucial role in the provided SPL. An evident example of nonrational low SPL was provided by the second alternative of shear wall period equation in 2003 ECOL. Unlike the minor site soil effect provided by 1993 ECOL edition, this parameter has now a crucial effect on the SPL increases in the order of soil flexibility. The \% change in SPL for the studied case reached $166 \%$ for flexible soil. In closure of these findings it seems to be that the safety of low to medium height buildings located in higher seismic zones and designed according to the earlier 1993 ECOL edition reconsidered.

- Extreme variation in the SPL obtained utilizing the three specified 2008 ECOL analysis methods is observed. The computer based multi MRS methods highly underestimate the obtained base shear in comparison with the other two methods especially for low to medium height buildings. This phenomenon is attributed to high reduction in design spectrum associated with high periods and to the practically unconditioned modeling of structures as bare frames ignoring the effect of infills. The consideration of infills especially for MRF buildings yielded high correlation in results between simplified and multi MRS analysis. The results of this section confirm that it is highly required to modify the seismic provisions to restrict the base shear obtained from multi MRS to those relying on simplified MRS as the case in many other codes.

- The response modification factor which depends mainly on the ductility, 
strength and damping of structures plays a crucial role in the obtained SPL. The ECOL specifies, for most cases, the highest modification factor in comparison with the other considered codes as Eurocode- 8 (main basis for $E C O L), U B C 97$ and $N B C C$. The simplified and multi MRS analysis carried out on cities match Cairo, in PGA and soil conditions, revealed that the SPL obtained using the ECOL was much less than the results obtained from other considered codes. The \% change in this dominator between ECOL and other codes could exceed $150 \%$. This variation was attributed to both response spectra and modification factor. The influential effect of the later alone was clarified through investigating irregular building using both ECOL and Eurocode-8.

\section{REFERENCES}

1- " The Egyptian Code for Calculation of Loads and Forces in Structural and Building Work" Housing and Building Research Center, Cairo, Egypt, 1993.

2- Naeim, F.: “ The Seismic Design Handbook" Structural Engineering Series, Nan Nostrand Reinhold, 1989.

3- "The Egyptian Code for Calculation of Loads and Forces in Structural and Building Work, ECOL 201 "Housing and Building Research Center, Cairo, Egypt, September 2003.

4- Eurocode-8: "Design of Structures for Earthquake Resistance "The European Committee for Standardization, Final Draft, December 2003.

5- Akkar, S., Bommer, J.: " Prediction of Elastic Displacement Response Spectra in Europe and the Middle East" Journal of Earthquake Engineering and Structural Dynamic , Vol. 36, pp. 1275-1301, 2007.

6- Adams, J., Atkinson, G.: “ Development of Seismic Hazard Maps for the Proposed 2005 Edition of the National Building Code of Canada " Can. J. Civ. Eng., Vol. 30, pp. 255-271, 2003.

7- Kappos, A.J.: " Evaluation of Behaviour Factors on the Basis of Ductility and Overstrength Studies " Journal of Engineering Structures, Vol. 21, pp. 823-835, 1999.

8- Whittaker, A., Hart, G., Rojahn, C.: " Seismic Response Modification Factors" Journal of Structural Engineering, Vol. 125, No. 4, pp. 438-444, 1999.

9- Genshu, T., Youngfeng, Z.: “ Inelastic Yielding Strength Demand Coefficient Spectra" Journal of Soil Dynamics and Earthquake Engineering, Vol. 28, pp. 1004-1013, 2008.

10- Arslan, M.H., Korkmaz, H.H.: “ What Is to Be Learned from Damage and Failure of Reinforced Concrete Structures During Recent Earthquakes in Turkey " Journal of Engineering Failure Analysis, Vol. 14, , pp. 1-22, 2007.

11- Marino, M., Nakashima, M., Mosalam, K.: “' Comparison of European and Japanese Seismic Design of Steel Building Structures', Journal of Engineering Structures, Vol. 27, pp. 827-840, 2005.

12- Kaushik, H.B., Rai, D.C., Jain, S.K.: “ Code Approaches to Seismic Design of Masonry-Infilled Reinforced Concrete Frames: A State-of-the-Art Review " Journal of Earthquake Spectra, Vol. 22, pp. 961-983, 2006. 
13- Heidebrecht, A.C.: “ Overview of Seismic Provisions of the Proposed 2005 Edition of the National Building Code of Canada " Can. J. Civ. Eng., Vol. 30, pp. 241-254, 2003.

14- Tinawi, R.: "An Overview of Fifty Years of Development for the Canadian Seismic Building Code "EGYQUAKE 3, Third Egyptian Conference on Earthquake Engineering, Cairo, 2004.

15- Haroun, M.A., Abdel Salam, M.N., Ismail,A.M.: " Fundamental Natural Period of Earthquake Resistant RC Buildings with Shear Wall Systems" Eleventh International Colloquium on Structural and Geotechnical Engineering, Egypt, 2005.

16- Abo El-Wafa, W.M.: " Effect of Masonry Infill Walls on the Natural Period of Reinforced Concrete Buildings" Journal of Engineering Science, Assiut University, Vol. 37, No.1, 2009.

17- Mwafy, A., Mahmoud, H.: "Performance of the Multi-Storey Structures Designed According to The Egyptian Provisions for Ductile Frame "Eleventh International Colloquium on Structural and Geotechnical Engineering, Egypt, 2005.

18-Megahed, A., Mahmoud, H.: " Performance of the Multi-Storey Structures Designed According to The Egyptian Provisions for Ductile Frame "Eleventh International Colloquium on Structural and Geotechnical Engineering, Egypt, 2005.

19- Abo El-Wafa, W.M.: “ Nonlinear Lateral Response of Masonry Infilled RC Buildings with Variable Parameter" Journal of Engineering Science, Assiut University, Vol. 37, No. 3, 2009.

20- Bommer, J., Pinho, R.: "Adapting Earhthquake Actions in Eurocode 8 for Performance-based Seismic Design " Journal of Earthquake Engineering and Structural Dynamics, Vol. 35, pp. 39-55, 2005.

21- " ETABS, Nonlinear version 9 Beta, Extended 3-D Analysis of Building Systems"' Computers \& Structures, Inc., Berkeley, U.S.A., 2005.

22- "SAP 2000, Nonlinear version 11, Static and Dynamic Finite Elements Analysis of Structure" Computers \& Structures, Inc., Berkeley, U.S.A., 2007.

23- Mainstone, R. J.: " Supplementary Note on the Stiffness and Strength of Infilled Frames." Building Research Station, Garston, Watford, 1974.

24- Asteris, P.G.: "Lateral Stiffness of Brick Masonry Infilled Plane Frames " Journal of Structural Engineering, Vol. 129, No. 8, pp. 1071-1079, 2003.

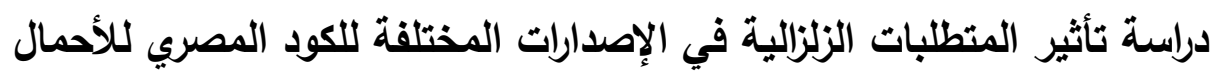

لقد كان ظهور الإصدار الأخير من الكود المصري للأحمال في سبتمبر 2008 دافعا قويا لإجراء دراسة تتاقش وتحلل النطورات المتتابعة للمنطلبات الزلزالية في هذه الإصدارات بدءا من إصدار عام 1993 وحتى إصدار 2008 مرورا بإصدار 2003 وتأثثراتها المختلفة علي درجة الحماية المطلوبة للمنشآت.

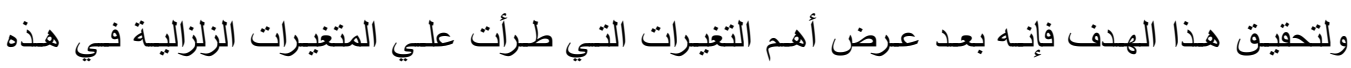

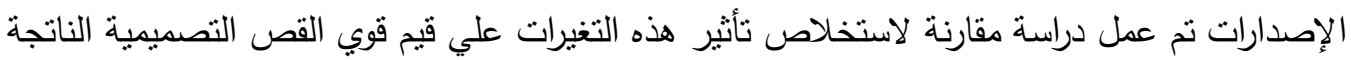

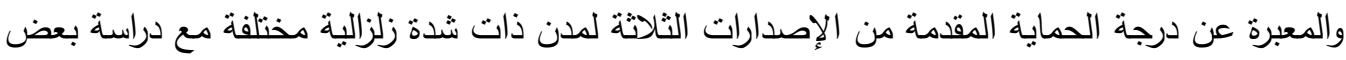


العوامل الهامة مثل اختلاف نوع المبني وتربة التأسيس وكذللك تأثثر تغير المعادلات المقدمة من الكود

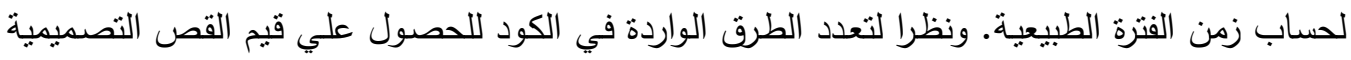

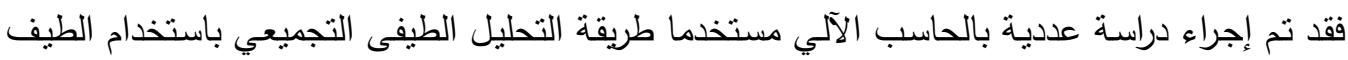
التصميمي المقدم من الكود المصري وطريقة السجل الزمني الديناميكي باستخدام سبعة زلازل حقيقية

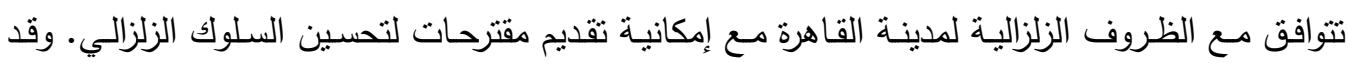

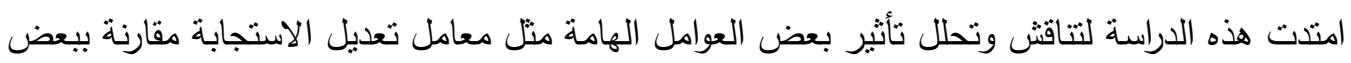
الأكواد العالمية مثل الكود الأوروبي (المرجع الأساسي للكود المصري) وكذلك كلا من الكود الأمريكي والكندي. ويمكن تلخيص النتائج التي تم الحصول عليها كالآتي:

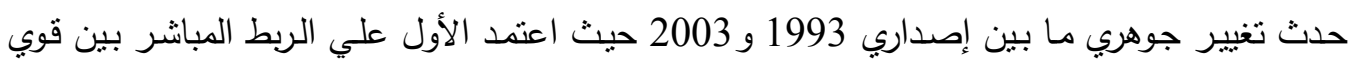

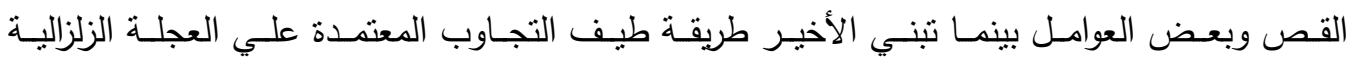

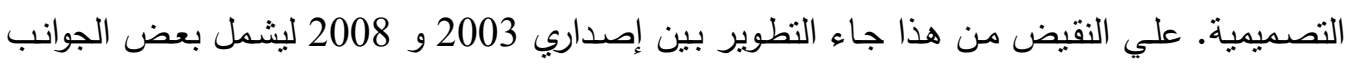

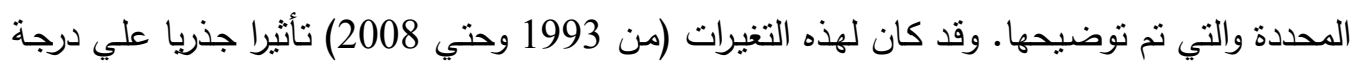

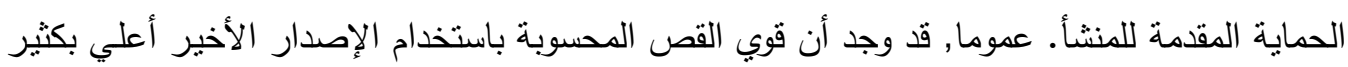

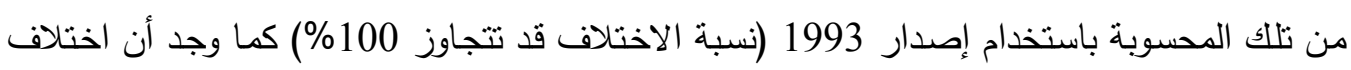

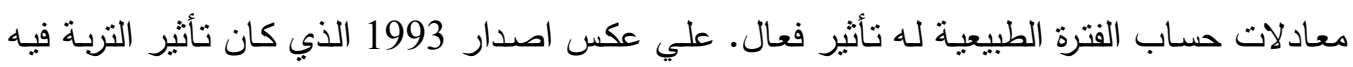

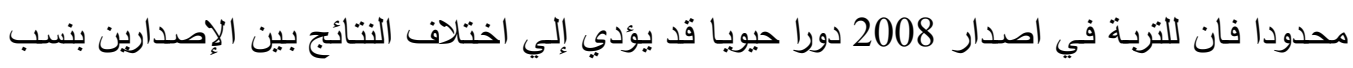

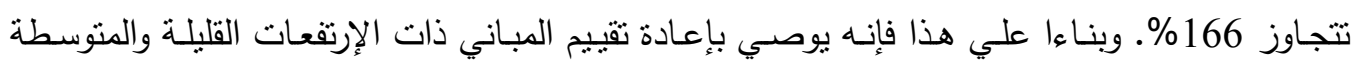
المصممة طبقا للإصدارات السابقة والواقعة في المناطق ذات الثندة الزلزالية المرتفعة.

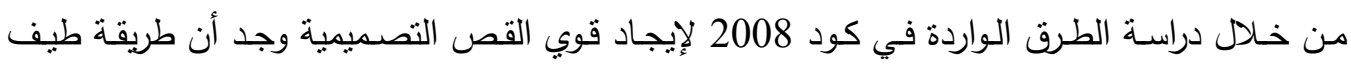

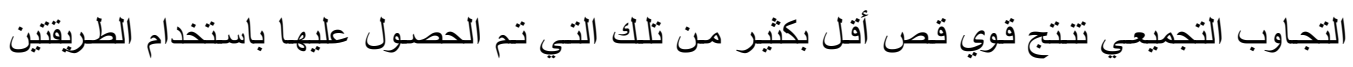

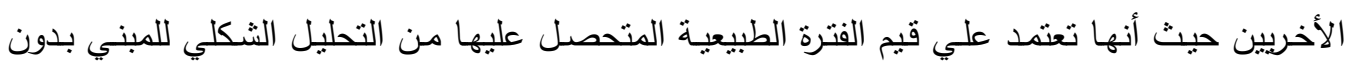

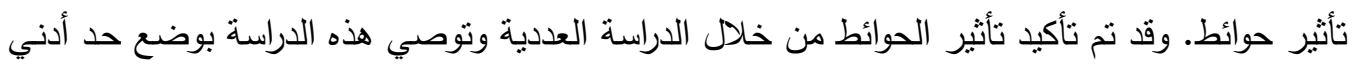
لقيم القص المتحصل عليها من هذه الطريقة منسوبا إلي طريقة الحمل الإستانيكي المكافئ مع استخدام معادلات الكود لحساب الفترة الطبيعية. وأخيرا بدراسـة وتحليل معامل تعديل الاستجابة رالذي يعتمد في المقام الأول علـي ممطوليـة المنشـأ.

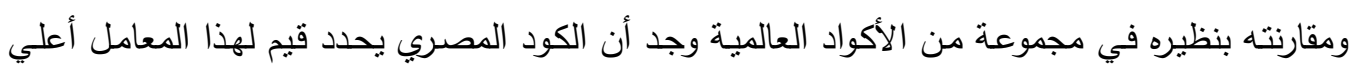

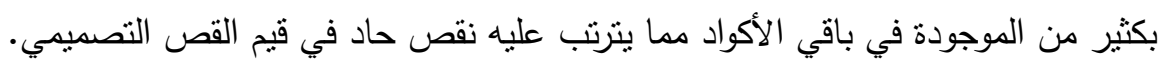

